
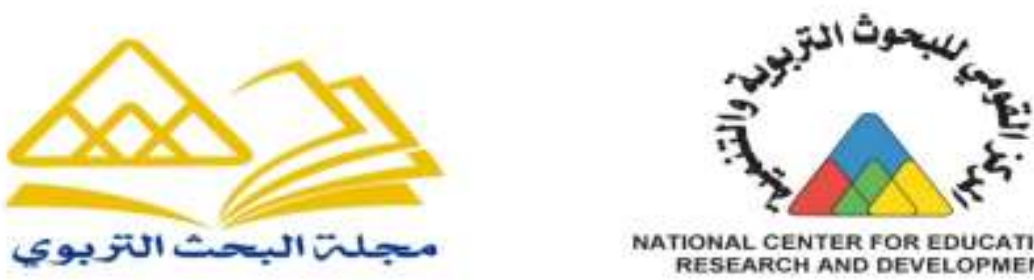

NATIONAL CENTER FOR EDUCATIONAL

RESEARCH AND DEVELOPMENT

\title{
دراسة أداء هدارس الفصل الواحد بمحافظتي الغربية والمنوفية
}

\author{
إlu \\ د/ فاطمة كمال سالم
}

$$
\begin{aligned}
& \text { الناش } \\
& \text { المىز: التومي للبحوث التربوتيتوالثميت بالتاهية } \\
& \text { جهويتي مص العيبت } \\
& \text { يوليو (r) }
\end{aligned}
$$




$$
\text { السنت العشقن }
$$

\section{دراسة أداء هدارس الفصل الهاحد بمصافظتبي النغوبية والنهوفية \\ Sld إعـ}

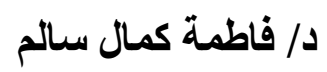

ملخص البحث: يعتبر التعليم استثمار مضمون العائد للقوى البشرية لأنه يقوم بدور

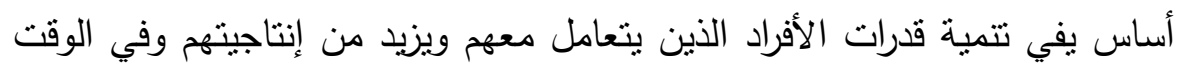
ذاته يعتبر القوة التي تقف وراء البنيان الاقتصادي للمجتمع (ْ). ومدارس الفصل الواحد عرفت في أمريكا وكان يتم تعليم فيها الدين والقراءة والكتابة فقط وعندما أرادو النهوض بالتعليم لجأوا إلى المدارس العامة المنتشرة في مصر والعالم كله. ومدارس الفصل الواحد خرجت عن الدور المنوطة بها لتعليم النشأ ولذلك تم القيام بهذا البحث للوقوف على الواقع الفعلي لمدارس الفصل الواحد والتعرف على: الوضع القائم بمدارس التعليم المجتعي- وروية الحقيقة الخاصة بأداء مدارس الفصل الواحد كما هي.

الدراسة التطبيقية: اتبعت الدراسة المنهج الوصفي التحليلي التطبيقي. وحدود الاراسة: الحدود المكانية: مديرية التربية والتعليم بمحافظة الغربية مديرية التربية والتعليم بمحافظة المنوفية. الحدود الزمنية: (شهر سبتمبر، شهر أكتوبر) لعام $\cdot r \cdot 11$

نـــائــج البحــث: عينة البحث تضمنت عدد (1/) إدارة تعليمية والمديرينان

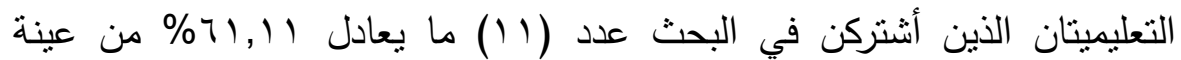

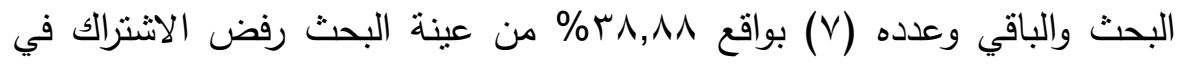
البحث لقناعته بعدم جدوى مدارس الفصل الواحد وأنها غير ذات جدوى ومضيعة

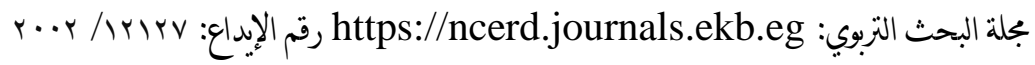

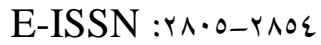

ISSN: $\cdot \wedge \wedge r-17 \wedge V$ 
للوقت والجهد ولا يوجد لها أي مردود على العملية التعليمية. وتوصل البحث للاتي: لا تسنطيع مدرسة الثقافة للمسنويات "الرابع والخامس والسادس" الإلمام بالمواد التي تقوم بتدريسها بشكل جيد. وغياب حضور العاملين بالمدرسة يخص مشرفة الفصل

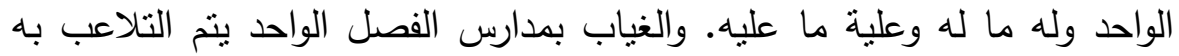

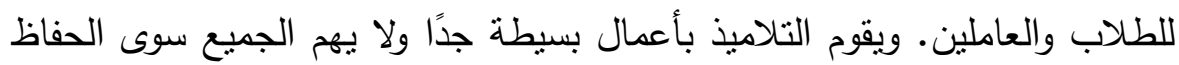
على العهدة المدرسية. وعدد الطلاب من ب:0 طلاب وغالبًا لا يحضرون. والموجين يرفضون التوجيه على مدارس الفصل الواحد وهذا نوع من الرفض الصامت لمدارس الفصل الواحد. والتلاميذ المنواجدين في المدارس فئة منهم يمكن تواجدها في المدارس العادية والفئة الأخرى تدخل مدارس التربية الفكرية. Summary: Education is considered to be a guaranteed investment of return to manpower because it plays a fundamental role that fulfills the development of the capabilities of the individuals with whom it deals and increases their productivity, and at the same time it is the force behind the economic structure of society ${ }^{(5)}$. One classes school known in amerce they were taught Arabic, math and debt only. Moreover, when they wanted academic education, they use to a public school. However, single-class schools deviated from the role assigned to them to educate the youth, and for this reason this research was carried out to find out the actual reality of onesemester schools and to get acquainted with: - Study the current situation in community education schools. Applied study: The study followed the descriptive, analytical, applied approach. And study boundaries: - Spatial boundaries: Directorate of Education in Gharbia

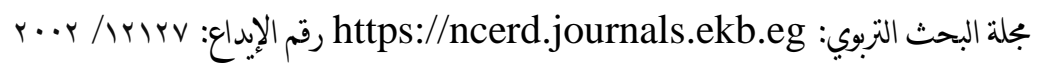

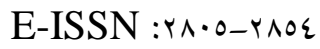

ISSN: $\cdot \Lambda \Lambda r-I T \Lambda V$ 


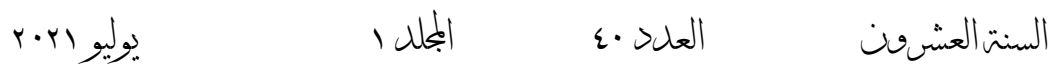

Governorate, Directorate of Education in Menoufia Governorate - Time limits: (September, October) for the year 2018 AD. Results of the research: The research sample included (18) educational departments and the two educational directorates who participated in the research, a number (11) equivalent to $61.11 \%$ of the research sample and the remainder (7) by $38.88 \%$ of the research sample. Refusal to participate in the research because of his conviction of futility One-semester schools are useless, a waste of time and effort, and have no impact on the educational process. And the research reached the following: The Culture School for the "fourth, fifth and sixth levels" cannot be familiar with the subjects that it teaches well. And the absence of school personnel attending belongs to the one-semester supervisor, and he has what he has and what he must do. Absence in onesemester schools is manipulated by students and workers. The pupils do very simple tasks, and everyone only cares about maintaining school custody. The number of students is 2: 5 students and they often do not attend. The mentors refuse to direct the one-semester schools, and this is a kind of silent rejection of the one-semester schools. And the students who are in schools, one class of them can be found in regular schools, and the other class enters schools of intellectual education.

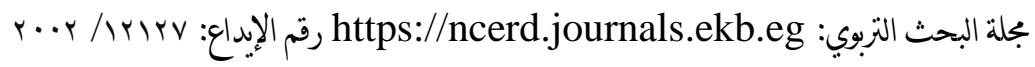

E-ISSN :YN・O-YNO\&

ISSN: $\cdot \wedge \Lambda \mu-17 \wedge V$ 


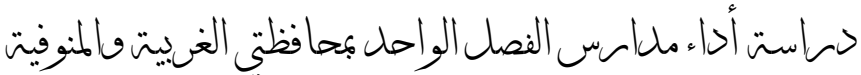

\section{دراسة أداء هدارس الفصل الواحد بمحافظتي الغربية والمنوفية إعــاد/ دـ داطمة كمال سالم}

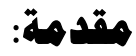

كما يعتبر التعليم استثمار مضمون العائد للقوى البشرية لأنه يقوم بدور أساس يفي تتمية قدرات الأفراد الذين يتعامل معهم ويزيد من إنتاجيتهم وفي الوقت ذاته يعتبر القوة التي تقف وراء البنيان الاقتصادي للمجتمع (o) ولكن مدارس الفصل الفيل الواحد خرجت عن الدور المنوطة بها تطليم النشأ للأسباب الآتية: - أصبح الفصل ملجأ لمن لا يريد العمل من هيئة المدرسين. - - التلاميذ لا تحضر للمدرسة ويكتفي بتسجيل أسمائهم. - مبتم قبول التلاميذ متخلفين عقليًا. - لا يتم تعليم التلاميذ بما يتفق والمناهج التي وضعتها الوزارة إما بسبب أنها

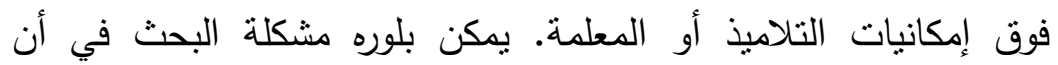
مدارس الفصل الواحد لم تحقق ما وعدت به من أنثأها إلى الآن. وكنتيجة لما سبق ظهرت مشكله أكبر وهي تسرب الطلاب من مدارس التعليم المجتمعي. ولذلك تم القيام بهذا البحث للوقوف على الواقع الفعلي لمدارس الفصل فلئ الواحد والتعرف على: دراسة الوضع القائم بمدارس التعليم المجتمعي. رؤية الحقيقة الخاصة بأداء مدارس الفصل الواحد كما هي.

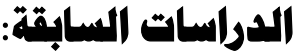

ومن الأهداف الداسة: تحديد المعوقات التي تواجه برنامج التعليم المجتمعي بمدارس الفصل الواحد لمواجهة التسرب الدراسي. تحديد مقترحات زيادة فاعلية وكفاءة برنامج التعليم المجتمعي.

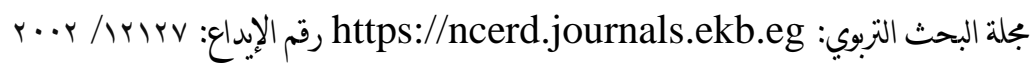

E-ISSN : YN・O-YNO\&

ISSN: $\cdot \wedge \Lambda ץ-17 \Lambda V$

$$
r \cdot \varepsilon
$$




$$
\text { السنت العشقن }
$$

\section{منهج البحث: يعتمد البحث على منهج المسح الاجتماعي.}

ومن نتائج البحث: توجد علاقة ذات دلالة إحصائية بين بعض المتغيرات

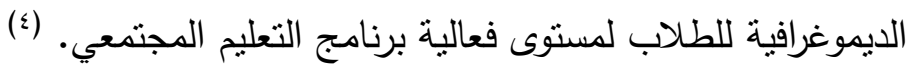
هدفت هذه الاراسة إلى: التعرف على واقع أداء مدارس التعليم الأساسي بمحافظة سوهاج في ضوء متطلبات التتمية المجتمعية لمحافظة سوهاج. نتائج البحث: ضعف الدور الذي يقوم به المجتمع المحلي في الأنشطة التتموية التي يتم بمشاركة المدرسة سواء داخل المدرسة أو خارجها - الجهود التتموية التي تقوم بها المدرسة هي مجرد مبادرات واجتهادات من إدارة المدرسة ولا توجد خطة تتمية مجتمعية محددة المعالم - وعلى ضوء هذه النتائج تم وضع التصور المقترح لتطوير أداء مدارس التعليم الأساسي في محافظة سوهاج في ضوء متطلبات التتمية

المجتمعية. (r) - (ب)

هدفت من الاراسة: هو التعرف على واقع التعليم المجتمعي. منهج البحث: يعتمد البحث المنهج الوصفي اعتمدت الدراسة على الاستبانة كأداة لجمع المعلومات والبيانات اللازمة لإتمام الدراسة. وقد توصلت الدراسة إلى مجموعة من النتائج أبرزها ما يلي: نوفير وسائل جذب لإنب

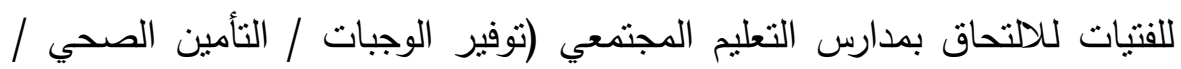
الإعانة الثهرية). - أن يتوافق تحديد مواعيد الدراسة بهذه المدارس مع الأوقات

التي تناسب الفتيات. (^)

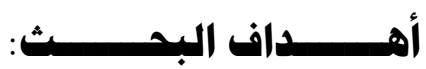

- الوقوف على أهم المشكلات التي تواجه مدارس الفصل الواحد. - تحليل خبرات كلا من فنلندا - كولومبيا - الهند - المكسيك للاستفادة منهم في

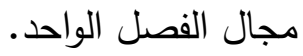

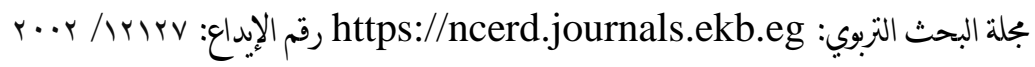

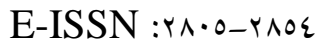

ISSN: $\cdot \wedge \wedge \mu-17 \wedge v$ 


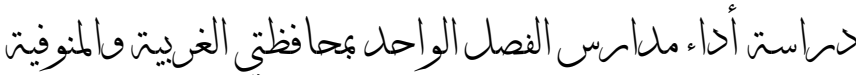

حــدود البحــث: يتمثل في إجراء البحث في محافظة الثرقية ومحافظة القليوبية. نتائــج الاراســـة: توصلت الدراسة الميدانية إلى انه يوجد العديد من المشكلات التي تواجه مدارس الفصل الواحد في مصر منها على سبيل المثال: - مشكلات مرتبطة بالمعلمة وتتمثل في: ضعف الإعداد العلمي والأكاديمي للمعلمات، تدنى النظرة المجتمعية لمعلمة الفصل الواحد، عدم مراعاة الفروق الفردية بين الدارسات، بعض المعلمات غير مؤهلات تربويا. - مشكلات مرتبطة بالتلامبذ وتتمثل في: الغياب وعدم الانتظام في الدراسة، الرسوب والتسرب من مدرسة الفصل الواحد، سوء المعاملة التي تصادفها الدارسة

من بعض المعلمات، ضعف العلاقة بين المعلمات والتلامبذ (v). يرهف البحث إلى: دراسة أهمية القراءة والكتابة بمدارس الفصل الواحد وضرورة تبني إستراتيجيات تدريس جديدة تتاسب خصائص واحتياجات الدارسات بتلك المدارس وتتوعها بتتوع السن والقدرات والاستعداد الميول والاتجاهات فأننا نجد الواقع التعليمي الحالي يغفل تللك الحقيقة وتواصل في استخدام الطرائق التعليمية في التدربس.

نتائسـج الدراســة: واستتادا إلى نتائج الدراسة الاستطلاعية التي قامت بها الباحثة على دراسات مدارس الفصل الواحد وكذللك نتائج بعض الدراسات السابقة تبين تدني مستوى الدراسات في اللغة العربية وعزوفهن عن دراستها بهذه المدارس (').

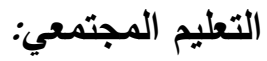

يعنى: مبادرة المجتمع المحلى بتعليم من لم تتح لهم فرصة التعليم بالمدرسة

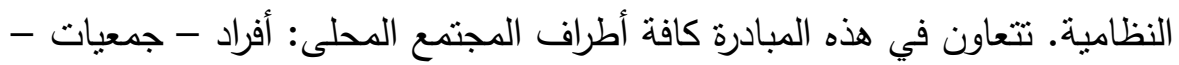
جهات حكومية وأهلية. (··) نظام التعليم للفصل الواحد يقوم على أساس تعلم

التلاميذ أنفسهم بأنفسهم لجعلهم قادرين على تحمل المسؤولية والعمل. (rاهئه

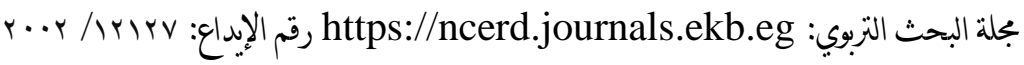

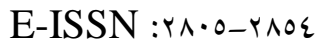

ISSN: $\cdot \Lambda \Lambda r-I 7 A V$ 


$$
\text { السنت العشنى }
$$

مدرسة الفصل الواحد / التعريف الإجرائي لمدرسة الفصل الواحد بأنها نمطا تعليميا موازيا للحلقة الأولى من التعليم الأساسي (الابتدائية)، وتضم تلميذات من أعمار ومستويات دراسية مختلفة في حجرة واحدة، وتقوم معلمتان للتدريس أحداهما للمواد الثقافية، والأخرى للمجالات المهنية، وهي تحقق الوصول إلى مستوى الثهادة

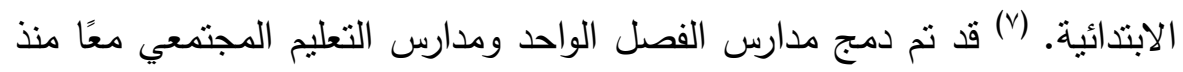
عام 90 ام وذللك بعد ثلاث مبتكرات في ورشة العمل مشتركة بين النموذجين. وتمت التوأمة في سياق المهارات التربوي والتدريب وسعة المبنى والموظفون وكانت

مهمة لتدعيم التطوير والتبديل في نموذج تعليم ال MOE (rar). التعريف بمدارس التعليم المجتمعي:

هو الأنشطة التعليمية التي تستهدف تحسين جودة التعليم والتي تتفذ من خلال شراكه فعالة وإيجابية من المجتمع ومؤسساته لتضمن استمرارية هذه الأنشطة، وتضافر الجهود الأهلية مع الحكومية لتقديم تدخلات ومساهمات عينية وغير عينية

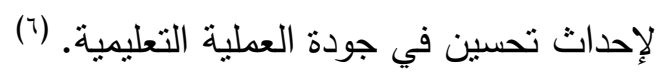
أنماط التعليم المجتمعي في مصر: مدارس المجتمع. -الفصل الواحد " الصيغة القديمة - الصيغة الجديدة " -مدارس الفصول متعددة المستويات التابعة لهيئة كير. - المدارس الصغيرة " التابعة لهيئة بلان التابعة لهيئة كير " -المدرسة صديقة

الفتيات " مدارس المبادرة “. (9)

يهذف التعليم المجتمعي إلى: -الهدف الأساسي لتعليم المجتمعي هي تقديم التعليم الابتدائي لتلاميذ الذين لم يلتحقوا بالتعليم الابتدائي أو تسربن منة وتتراوح أعمارهم بين 7-ـ إنة" من الفقراء في المناطق الريفية والحضرية.

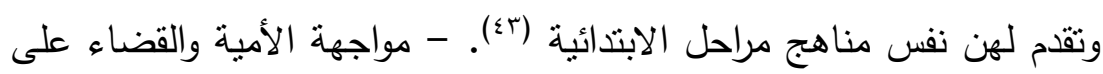

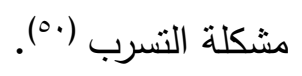

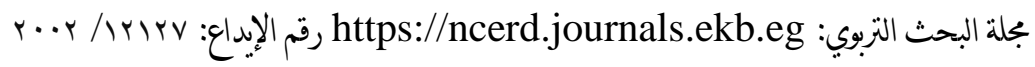

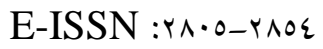

ISSN: $\cdot \wedge \wedge \mu-17 \wedge v$ 


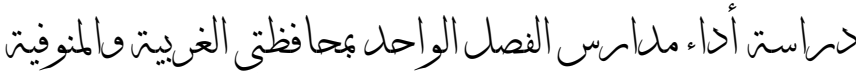

المعاييز والثروط التي يجب إتباعها لاختيار مكان مدارس الفصل الواحد: يجب أن تقع المدرسة في منطقة لا يقل عدد سكانها عن . .10 نسمة. -تكون المدرسة بعيدة عن الضوضاء. - تكون قريبة من مصدر الكهرباء. - يوجد بها حمام. - إلا تقل مساحتها عن • 11 متر مربع. - المبنى يجب أن يكون مجهز بالأدوات والأجهزة ويكون المبنى جيد الإضاءة والتهوية. - يجب أن تكون المسافة

بينها وبين أقرب مدرسة ابتدائي لا تقل عن r كيلو متر . (r) نشأة مدرسة الفصل الواحد: ترجع نشأة المدارس المتعددة المستويات إلى القرن الثامن عشر في الولايات المتحدة الأمريكية، حيث ظهرت مدارس المقاطعات District School

(?) المتعددة.

\section{تاريخخ التعليم الأمريكي ونهاية مدارس الفصل الواحد:} لا أحد فعل أكثر من Mann للتَّاسيس عقول الشعب الأمريكي، المفهوم بأن التعليم يجب أن يكون غير طائفي عالمي، يحرر، وبأن أهدافه يجب ان تكون كفاءةً اجنماعية، ميزة المدنية، والثخصية، بدلًا من مجرد التعليم أو تقديم غايات طائفية

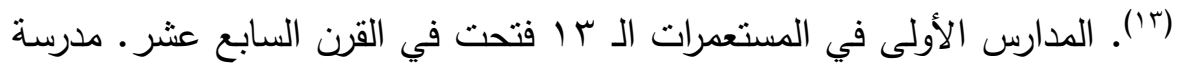
بوسطن اللاتينية كانت المدرسة العامة الأولى التي فتحت في الولايات المتحدة، في

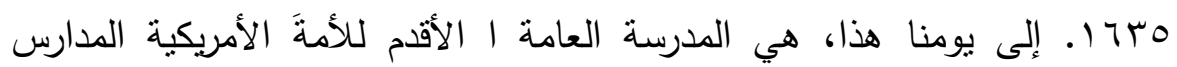

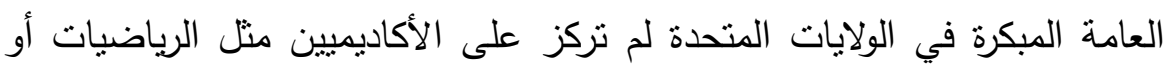

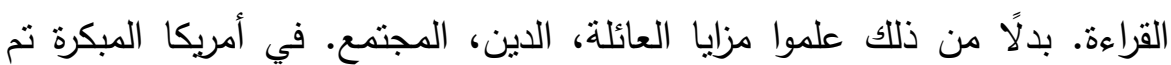
تعليم البنات كيفية القراءة ولكن لم يتعلمن الكتابة. بمنتصف القرن التاسع عشر، أصبح الأكاديميين المسؤولون الوحيدون عن المدارس العامة. في الجنوب، المدارس العامة لم تكن مشتركةً أثناء . . 17 ومبكرًا . . IV دفعت الأسر الغنية لمعلمون

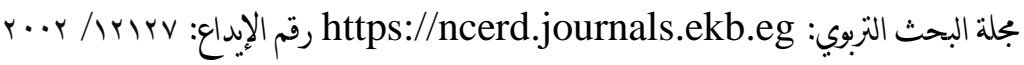

E-ISSN : r

ISSN: $\cdot \Lambda \Lambda r-I 7 A V$ 
السنت العشنف

خاصون لتعليم أطفالهم. المدارس المشتركة ظهرت في القرن الثامن عشر . علمت هذه المدارس الطلاب في كل الأعمار في غرفة واحدة مع معلم واحد. التعليم في

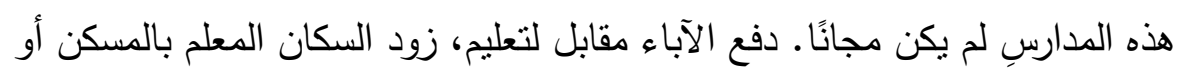

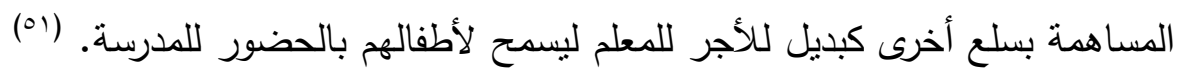

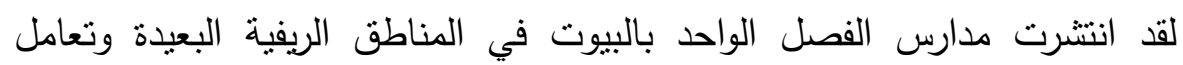
المعلمون مع الطلاب ذو القدرات المختلفة والأعمار المنباينة النظام الإنصاتى وهي طريقة تعليم التي أصبحتْ شعبية على المقياس عالمي أثناء أوائل القرن التاسع عشر • هذه الطريقة كانت "معروفة كذلك التعليم المتبادل" (mutual instruction") أَو" طريقة (Bell-Lancaster") بعد المربين البريطانيين الدكتور ( Dr Andrew

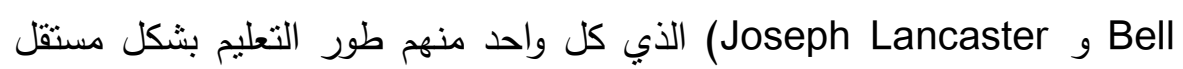
حوالي V91 ا. كأطفال الأكبر سنًا في الأسر تعلم الأصغر سنًا التلاميذ القادرون في هذه المدارس أصبحوا ' المساعدون للمعلمِ، وعلموا الطلاب آخرين ما الذين تم تعليمهم. (דr) التعليم في المستعمرات الأمريكية بدأ كمسعى ديني. في القرن السابع عشرِ، شدد مستوطني نيو إنجلند البيوريتانيون بأن كل شخصِ يتعلم القراءة التوراة.

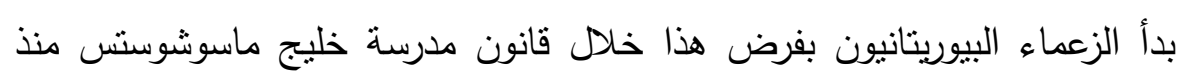

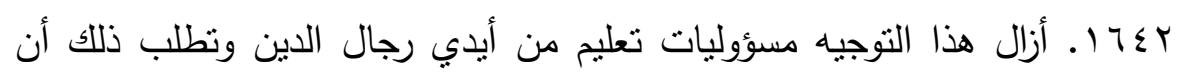
يعلم الآباء أطفالهم كيف يقرؤون ويكتبون. خطط جيفيرسن للتعليم الأكثر مركزية

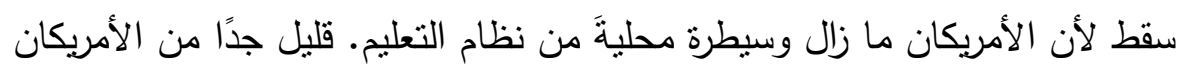
أرادوا أن يكون هناك إنترافًا حكوميًا أولي ومدرسة المستوى العالي للتعليم. لأن الأمريكان ما زالوا بساندوا مغامرات تعليم خاص وسيطرة محليةً على نظام التعليم. تعليم النساء حدد بالقراءة والكتابةِ الأولية سويا مع تطوير مهارات homemaking (الصناعات المنزلية) نحو نهاية القرن الثامن عشرِ. كما أنهى هيله

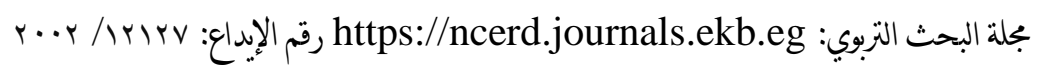

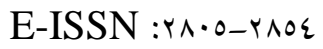

ISSN: $\cdot \wedge \Lambda \mu-17 \wedge V$ 


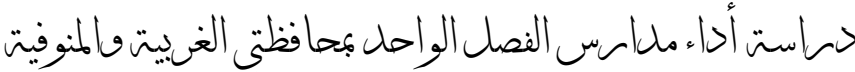

جورج واثنطن مدته كرئيس الولايات المتحدة الأمريكية الأول، بترك بضعة كلمات منفصلة. خطاب وداع واشنطن في V99 حدد العديد من التوصيات كانت من اجل مستقبل بلاده. من بين هذه الاقتراحات كان نظام تعليم عام. أمر واثنطن زعماء الأمريكان بنشر مؤسسات عامة لنشر المعرفة. القرن التاسع عشر شهد تحول صارم في المواقف نحو التعليم العام في الولايات المتحدة. (10)وجرت مناقثة أن التعليم العامة العام كان هو أفضل طريق لتحويل أطفال الأمةَ المنفلتين إلى المواطنين الجمهوريين العاقلين المنضبطين، وربح Mann مواققة واسعة لانتشار بناء المدارس العامة من المجددين، خصوصًا بين الزميل .Whigs تبنت أكثر الولايات نسخةَ واحدة أو واحدة أخرى من النظام الذي أسس في ماسوشوستس، خصوصًا البرنامج لـ "مدارس طبيعية" "normal schools" لتدريب المعلمين المحترفين. (rr) إن القرن التاسع عشر في أغلب الأحيان مدعو باسم "فترة مدرسة مشتركة" لأن التعليم الأمريكي انتقل من مسعى خاص كليًا إلى التوفر العام. لئ الطلاب القادرون على حضور مدارسِ القرن التاسع عشر المبكرة واجهت العديد من التحديات. الأطفال تحت عمر خمسة كانوا في أغلب الأحيان اختلطت أوقات فيها مع البالغين في العشرينات. إضافة إلى ذلك، قاعات دروس ازدحمت كثيرًا واشتملت بحدود ثمانون طالب في نفس الوقت. ولو أن منتصف القرن التاسع عشر مبكر رأى إلى العديد من الأطراف أن بدعوا لإنثاء المدارس العامة وفكرة التدريس الحكومية التمويل. ما زالَ يعطي ردّ فعل قاسي: ( ) قلق دافعي الضرائب بأن التعليم عام يؤدي إلى ضرائب أعلى أو بأنه بشكل خاطئ يخرجون المال من جيوب الطبقة العاملة لتمويل تعليم الأغنياء. r) أكدت الكنائس بأنَ المدارس العامة تخفق في تعليم الدين بما فيه الكفاية.

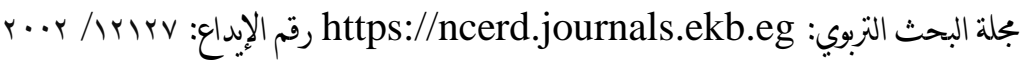

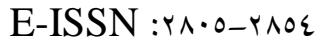

ISSN: $\cdot \Lambda \Lambda r-I 7 \wedge V$ 
السنت العشنف

r) خاف معلمين المدارس الخاصة بأنهم يواجهون رواتب مخفضة أَو حتى يفقدوا

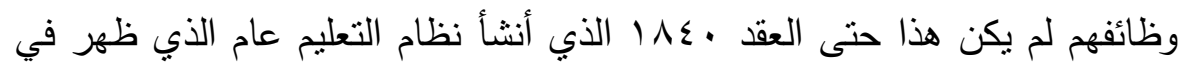
الولايات المتحدة. بنى المصلحون مدارس مشتركةَ تبدأ على حسب الولايات. روج رواد إصلاح التعليم التربوي انه وسيلة لتحسين الفرص الاقتصادية لكل الأمريكان ولخلق والرابطة المشتركة بين المواطنين والسكان المتتوعين جدًا. مؤيدو المدرسة العامة أرادوا إيجاد مدارس ابتدائية حرة منوفر بالكامل إلى كل الأطفال الأمريكان. قاتل Mann لضمان التمويل الضريبي للمدارس العامة ولمنع التعليم الديني وفْصله عن التعليم العام. أسس Mann المعلم أيضًا يدرب للكليات ويطول السنة الدراسيةَ. أسس Mann أيضًا تدريب معلمين الكليات وإطالة السنة الدراسيةً. انجازات Mann الأعظم كان ودوره في بدء حركة المدرسة المشتركة: مبكرًا في العقد ·ع 1، قضى Mann وقت كبير يسافر في كافة أنحاء أوروبا يدرس أنظمةً

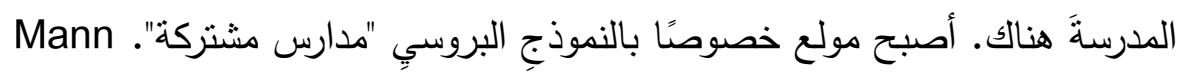
تعاطف مع وجهة النظر البروسية التي كانت تدعو إلى أن كل الناس يجب أن لن يحصلون على نفس مستوى التعليم. من هذه التجربة عمل Mann لإنشاء شبكة المعلمين المدربون جيدًا لجلب تعليم أولي "مشترك" إلى كل أطفال ماسوشوسنس.

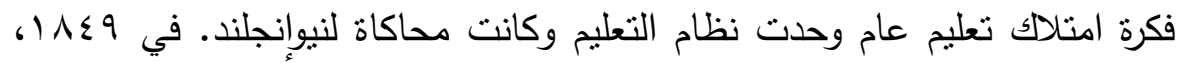
كونيكتيكت تبنت نظام مدرسة مشترك مشابه للواحد المطبق في اسوشوستس. في ror اذهب ماسوشوستس إلى حد لتشريع قانون حضور إلزامي. تأسيس الفصول

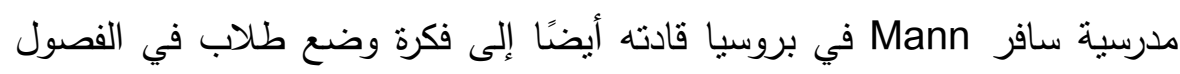
مستتد على العمر والقدرة على التعلم. فرض Mann هذه الفكرة المعروفة بإدراج

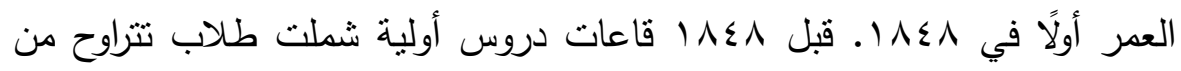
صغار ب-ـ ا سنة. عندما قدم Mann تصنيف العمر، تفاوتات الأعمار الكبير في

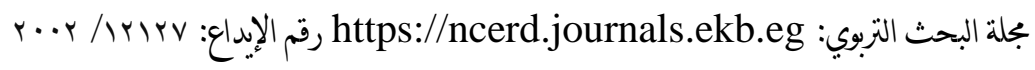

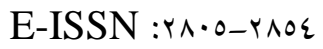

ISSN: $\cdot \wedge \Lambda \mu-17 \wedge V$ 


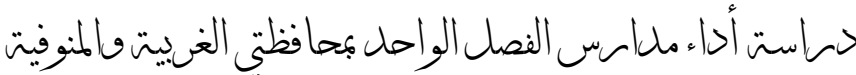

قاعات الدروس اختفت تقريبًا. النظام كان ناجح بينما سمح للطلاب التعلم مع أطفال في نفس عمرهم الزمني وهذا أعطاهم الفرصةَ لـ “لتخرج" إلى الدرجةِ التالية الذي أعطاهم شيء للعمل تجاهه وإحساس بالإنجاز عندما أنهوا كل درجة. في تقرير Mann السنوي العاشر لسكرتير لمجلس الولاية ماسوشوستس للتعليم

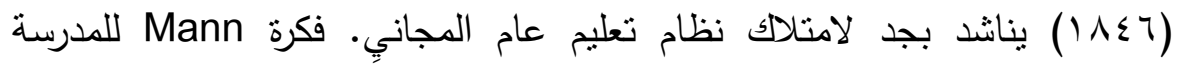
مشتركة كانت تللك المفتوحةً لكل أطياف الأمريكان وتخدم لتحطيم امتيازات الطبقات. كما Mann ناقش في هذا التقرير، نظام التعليم المشترك على انه كان

أفضل طريق لضمان الوحدة الاجتماعية والوطنية. (1)

بناء علية أصبح (Massachusetts) وزير التعليم في INV وعمل ( Horace)

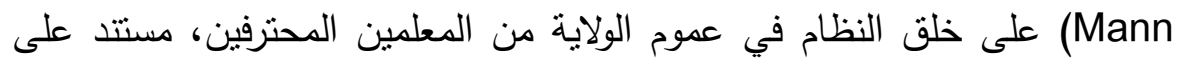
النموذج البروسي (Prussian model) لـ (مدارس مشتركة). بروسيا كانت تحاول تطوير نظام لتعلي عن طريق الفصول العامة التي فيها كل الطلاب عندهم الحق في نفس المحتوى التعليمي. ركز (Mann) أوليًا على التعليم الأولي وعلى تدريب المعلمين. الـ (مدارس مشتركة) كسبت حركة وقوة سريعة عبر الثمال.

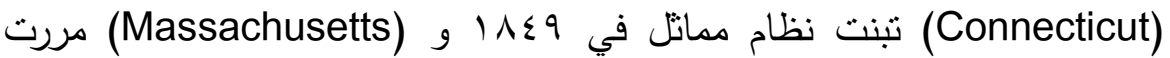
قانون الحضور إلزامي في Mor ا. . جذب أسلوب محاربة Mann دعم الطبقة المتوسطة العريضة. (rv) (rv) التقنية المهمة التي تعلمها (Mann) في بروسيا

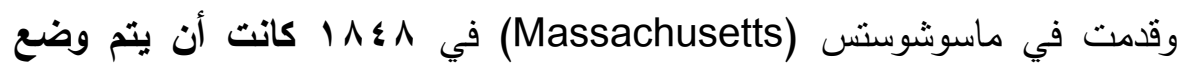
الطلاب في الفصول على أساس العمر الزمني. وتم تقبيمهم حسب العمر إلى الفصول المختلفة وتقاموا خلالها بغض النظر عن اختلافات الكفاءة. بالإضافة إلى استعمال طريقة المحاضرة الثائعةَ في الجامعاتِ الأوروبية الذي نطلب من الطلاب الاستماع واستلام التعليم بدلًا من أخذ دور النشيط في تعليم أحدهما الآخر.

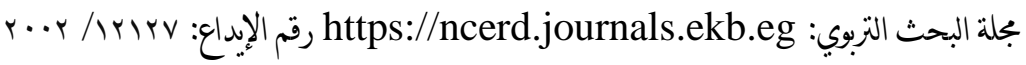
E-ISSN : r ISSN: $\cdot \Lambda \Lambda r-I 7 A V$ 
السنت العشنف

سابقًا في أغلب الأحيان المدارس كان عندها مجموعات الطلاب الذين تراوحوا في العمر من 7 إلى \& ا سنة. مع إدخال تصنيف العمر اختفت تقريبا قاعات (الفصل الواحد) متعدد العمر. (\&)؛ بعض الطلاب تقدموا بدرجتهم وأكملوا كل المقررات المطلوبة منهم ولذا كان لا بد أن تعرض المدرسة الثانوية. هذا وتخرجوا ومنحت شهادة الإكمال. هذه عملت على نحو منزايد طقوس التخرج من الكلية ومراسم التقلد. (rr) أكثر الولايات مررت تعديل دستوري مسمى تعديلات بلين يمنع أموال الضرائب أن تستعمل لتمويل المدارس ضيقة الأفق (parochial schools). المدارس

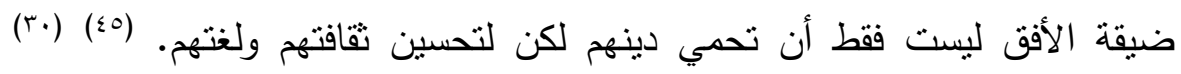
عندما وصل الجمهوريون إلى السلطة في الولايات الجنوبية بعد لیTV النشأوا

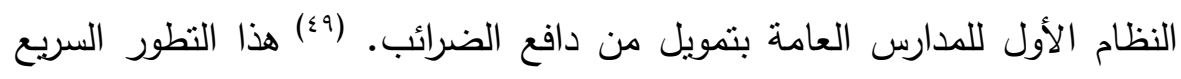

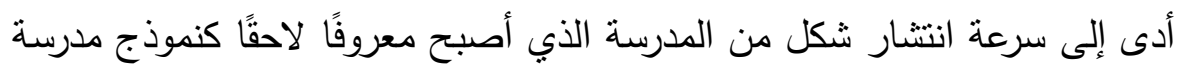
المصنع. التدريس المجاني كان متوفر خلال البعض من الدرجات الأولية. خريجو هذه المدارس يمكن أن يقرؤ ويكتبوا مع ذللك ليس دائمًا مع الدقة العظيمة. (ז') القوانين الإلزامية: بحلول الـ . .9 1، ــ ولاية كان عندها قوانين التدريس الإلزامية أربعة كانت في الجنوب. ثلاثون ولاية طبقت قوانين التدريس الإلزامية الذي تطلبت

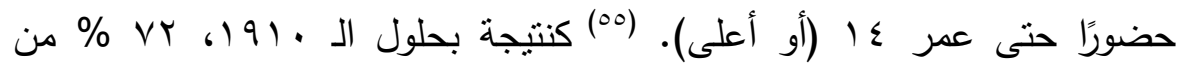

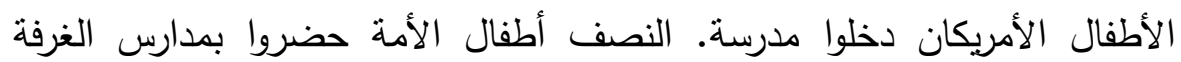
الواحدة. بحلول الـ 1919 طالبت كل الولايات الطلاب بإكمال المدرسة الابتدائية.

العصر التقدمي: النخبة الاجتماعية في العديد من المدن في العقد .119 قادت حركةَ الإصلاح. هدفهر كان أن ينهي سبطرة الحزب السياسي بشكل دائم على لى المدارس المحلية لتحقيق المنفعة لوظائف الرعاية وعقود الإنشاء التي ننأتا عن

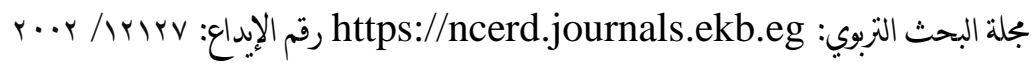

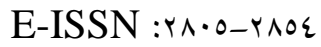

ISSN: $\cdot \wedge \Lambda \mu-17 \wedge V$ 


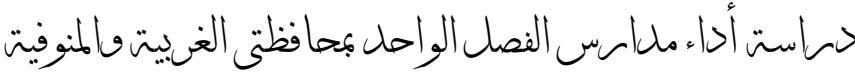

سياسة ward التي امتصت وعلمت ملايين المهاجرين الجدد. (ra) العصر التقدمي

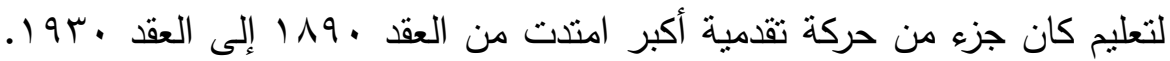
العصر بارز كان التوسع مثير في عدد المدارِس والطلاب خصوصًا في الددن الحضرية السريعة النمو. بعد . 191 بدأ مدن أصغر ببناء الددارس العليا أيضًا.

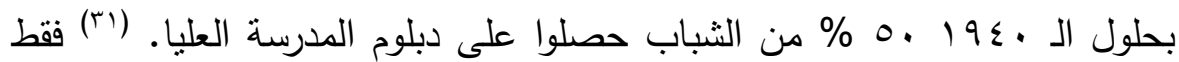
في فترة الجيل التعليم العام ترك وراءه نظام إلى حد كبير نظام مكرس لتنريب الأطفال المهارات الأساسية ليعرفة القراءة والكتابة والانضباط المطلوب للمواطنين

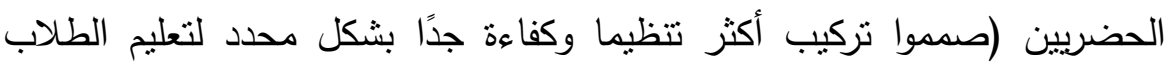
المهارات المتخصصة العديد التي يتطلبها المجتمع الصناعي الحديث.) من ناحية

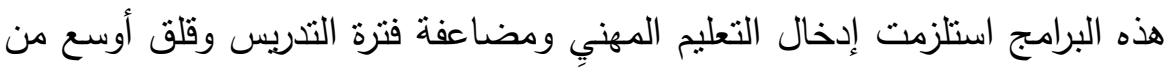

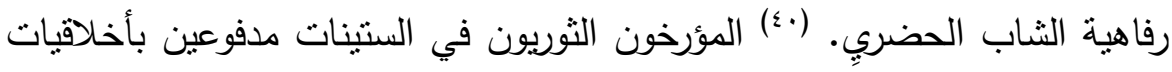
معاداة البيروقراطية للبسار الجديد أستهجن ظهور أنظمة المدرسة البيروقراطية. ناقثوه بهدف قمع التطلعات الصاعدة للطبقة العاملة. (10) لكن المؤرخين الآخرين أكّدوا عل ضرورة بناية الأنظمة القياسية غير المسيسة. (.؛ قادت نخبة مدينة نيويورك إصلاحات تقدمية. المصلحون وضعوا نظام بيروقراطي مدار من قبل خبراء وطلبوا الخبرة من المعلمين المتوقعين فتحت الإصلاحات الطريق أمام الاستعانة بالمعلمين الكاثوليكيين واليهود الأيرلنديين الأكثر ، الذين أثنتوا براعة في الأدين إدارة الخدمة المدنيةِ يَختبرُ والحصول على أوراقَ الاعتماد الأكاديميةً الضروريةًَ.

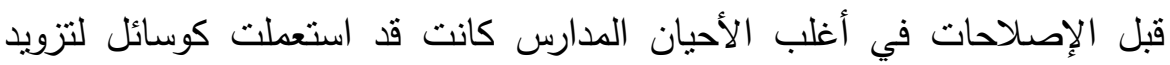
بوظائف الرعاية لفرق جنود المشاة. التأكيد الجديد ركز على توسيع الفرصِ

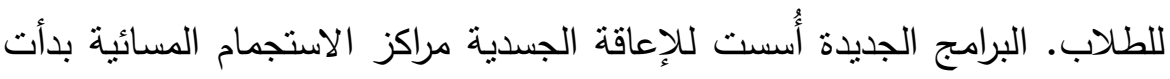

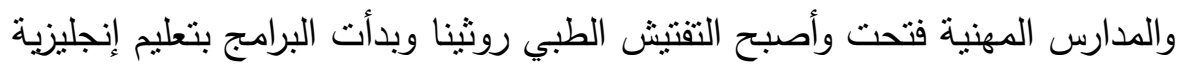

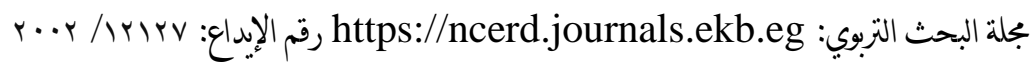

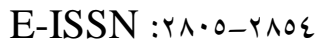

ISSN: $\cdot \Lambda \Lambda r-I 7 A V$ 
كلغة ثانية ومكتبات المدرسة العامة فتحت. (9") بحلول الـ . .9 1، اب ولاية كان

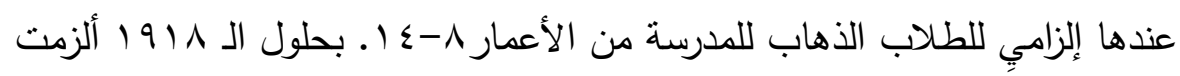
كل ولاية الطلاب إكمال المدرسة الابتدائية. فكرة التعليم التقدمي بعلم الطفل للوصول إلى كامل إمكانياته وتطوير (رفع) نشاطه والمشاركة في المجتمع الديمقراطي وبدأ في أواخر العقد . . 1 أو وأصبح واسع الانتشار بالثنالثينات. جون ديوي كان مؤسس هذه الحركة. (10) ديوي والتعليم التقدمي: العالم النظري التربوي

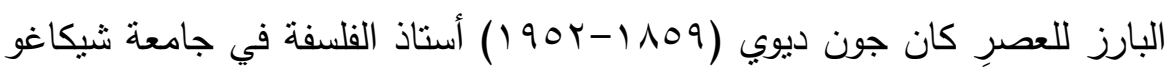

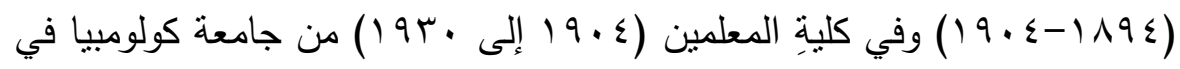
مدينة نيويورك. (^^) ديوي كان يقود ينصر "تعليم تقدمي" وكتب العديد من الكتب

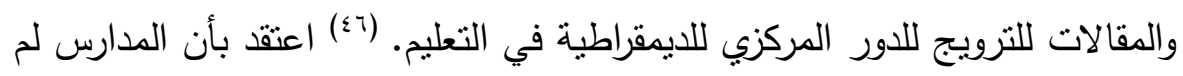
تكن فقط مكان للطلاب لكسب المعرفة المحدودة لكن أيضًا مكان لهم لتعلم كيف يعيشون. هكذا هدف التعليم لإدراك إمكانيةِ الطالب الكاملةَ والقدرة لاستعمال تلك المهارات للاستفادة الأعظم منها. ديوي لاحظ ذلك "لتهيئه التلاميذ للحياة المستقبلية

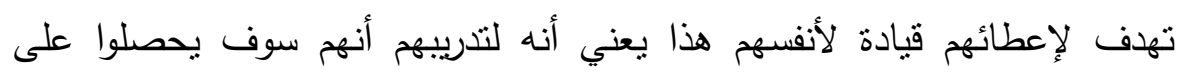

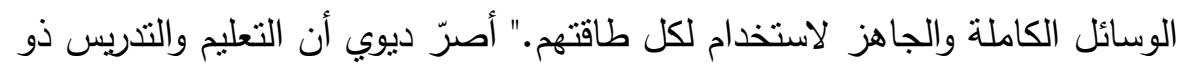
دور فعال في خلق التغير الاجتماعي والإصلاح. لاحظ "أن العملية التعليمية للاشتراك في الوعي الاجتماعي والتي تعدل النشاط الفردي على أساس هذا الوعي

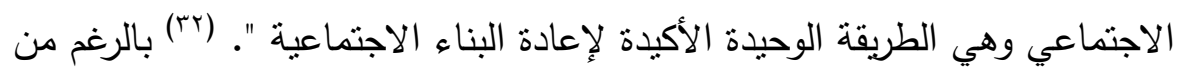

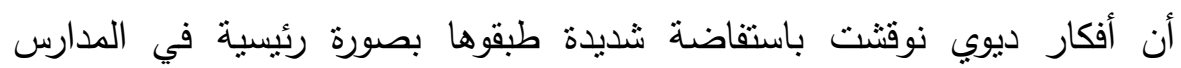
التجربيية الصغيرة التي ربطت بالكليات التعليمية. في المدارس العامة ديوي والعلماء

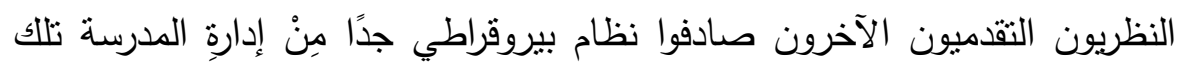
النماذج لم تكن قابلةَ للطرق الجديدة. (جا') نظر ديوي للمدارس العامة وتدبيرهم

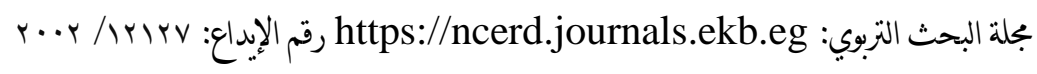

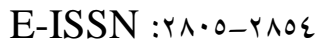

ISSN: $\cdot \wedge \Lambda \mu-17 \wedge V$ 


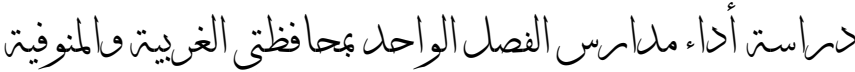

الضيق بالازدراء كما انه غير ديمقراطي وعقيم التدبير. في هذه الأثناء مدارس المختبر مثل مدارس مختبر جامعة شيكاغو كانت مفتوحة أكثر بكثثر إلى الفكر والتجريب الأصلي. لم يكن ديوي مرتبط فقط بمدارس المختبر لكَنَه أيضًا كان مقتتع لئر

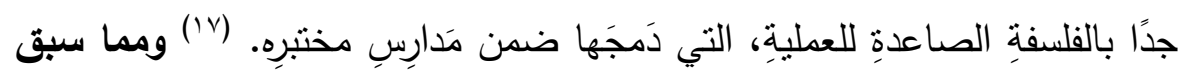
يتضح أن مدارس الفصل الواحد كانت تقوم بتعليم شئون الدين فقط ثم أصبحت تعلم القراءة إلى جانب شئون الدين تم تطورت لتعلم القراءة والكتابة وشئون الدين وعندما بدا الأمريكان يسعون لتعليم الأكاديمي قاموا بإنشاء المدارس العامة

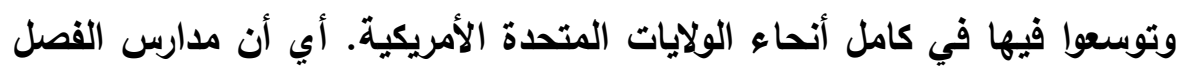
الواحد كاتت تماثل الكتاتيب في مصر من معظم النواحي أن لم يكن جميعها. تاريخ التعليم الانجليزي ومدارس الفصل الواحد ومدارس المنزل: قبل وصول أوغسطين من كانتربري إلى إنجلترا عام 09V، كان التعليم شأنًا شفيًا، أو اتبع النموذج الروماني في الثتات والعائلات المتكاملة. ارتبطت أقدم المدارس المنظمة المعروفة في إنجلترا بالكنيسة. أنشأ أوغطين كنيسة في كانتربري (والتي أصبحت فيما بعد دير القديس أوغسطين) في عام 091، والتي تضمنت مدرسة لدراسة النصوص الدينية، وفي ع ـ ج انضمت إليها مدرسة أخرى فيما يعرف الآن بكاتدرائية روتتستر • تم إنشاء المزيد من المدارس في جميع أنحاء الجزر البربطانية في القرنين السابع والثامن، بشكل عام بإتباع أحد شكلين: مدارس القواعد لتعليم

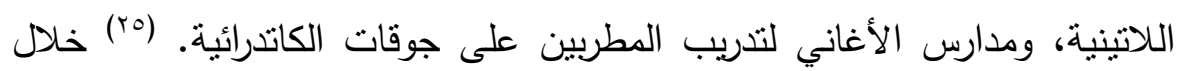
العصور الوسطى، تم إنشاء مدارس لتعليم قواعد اللغة اللاتينية لأبناء الطبقة الأرستقراطية المخصصة للكهوت أو العمل الرهباني مع وزارة الحكومة أو القانون. تم إنشاء جامعتين بالاشتراك مع الكنيسة: جامعة أكسفورد، تليها جامعة كامبريدج، للمساعدة في التدريب الإضافي لرجال الدين المسيحيين الكاثوليك. تم إصلاح نظام

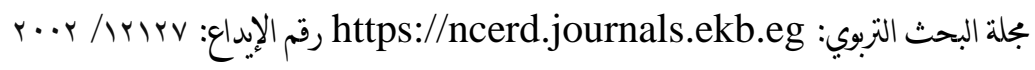

E-ISSN : r

ISSN: $\cdot \Lambda \Lambda r-I 7 A V$ 


$$
\text { السنت العشقن }
$$

"المدارس النحوية الحرة" في عهد إدوارد السادس. هذه أيضًا قدمت طرقًا نحو الكهنوت. كانت التلمذة الصناعية هي الطريقة الرئيسية للثباب للخول المهن العملية. كان للإصلاح البروتستانتي تأثير كبير على التعليم ومحو الأمية في إنجلترا، حيث شجع على قراءة الكتاب المقدس باللغة الإنجليزية ("العامية"). المدارس المستقلة لها تاريخ طويل في إنجلترا؛ نم إنشاء بعضها قبل القرن العاشر . أقدمها هي مدرسة كينجز، كانتربري، التي تأسست عام 09V. كان العديد منها مدارس خيرية. قامت مجموعة من هذه المدارس، بعد ذلك بكثثير، باستذعاء اسم "المدرسة العامة" للإثشارة إلى أنها مفتوحة للجمهور بغض النظر عن المعتقدات الدينية. في تيودور إنجلترا، أعاد إدوارد السادس تتظيم مدارس القواعد وأسس بهس بهن مدارس جديدة بحيث كان هنالك نظام وطني "لمدارس القواعد المجانية". كانت هذه

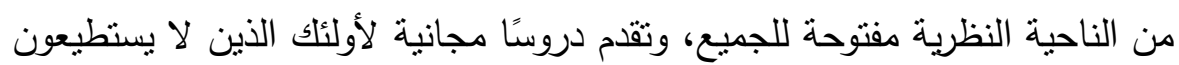

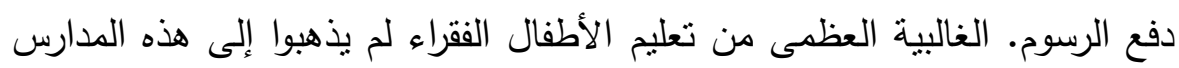

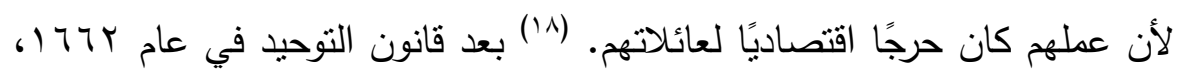

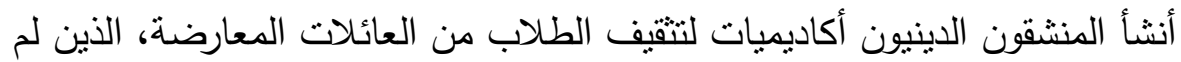
يرغبوا في الاشتراك في مواد الكنيسة المؤسسة في إنجلترا. لا نزال بعض هذه

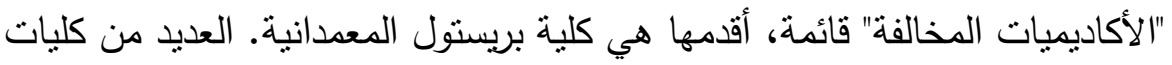
أكسفورد (Regent's Park و Mansfield و Harris Manchester) هي أيضًا من نسل هذه الحركة. (or) قامت المديرات بالمدارس عادةً بتدريس الثلاثة روبية

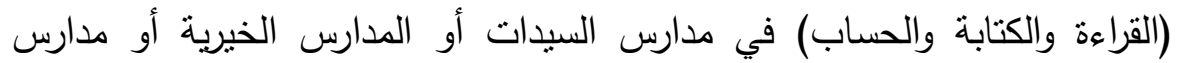
القرى غير الرسمية. يقول المؤرخ ديفيد ميتش أن العمل الخيري الخاص كان مصدرًا رئيسيًا للتمويل بحلول أربعينيات القرن السادس عثر ، وفي هذا الصدد كانت إنجلترا ميزة بين الدول الحديثة. (๕) في القرنين الثامن عشر والتاسع عشر، أسست جمعية

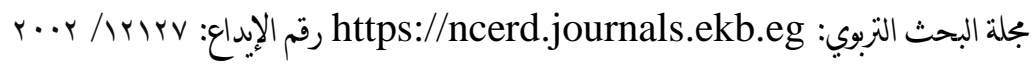

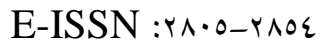

ISSN: $\cdot \wedge \Lambda \mu-17 \wedge V$ 


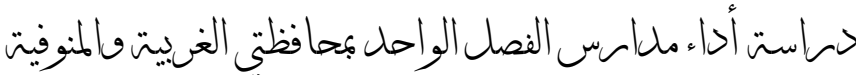

تعزيز المعرفة المسيحية العديد من المدارس الخيرية للطلاب الفقراء في الفئة العمرية من V إلى | 1 عامًا. شكلت هذه المدارس الأساس لتطوير المفاهيم الحديثة للتعليم الابتدائي والثانوي. كانت الجمعية أيضًا من أوائل مقدمي تعليم المعلمين. (اء) استخدم رايكس جريدته للترويج للمدارس وتحمل معظم التكلفة في السنوات الأولى. بدأت الحركة في يوليو . IVA في منزل السيدة ميريديث. وحضر الأولاد فقط، وسمعت دروس الأولاد الأكبر سنًا الذين دربوا الصغار. في وقت لاحق، حضرت الفتيات أيضًا. في غضون عامين، تم افتتاح العديد من المدارس في جلوستر وحولها. نشر رايكس حسابًا في ب نوفمبر س V V لمدرسة الأحد في ورقته،

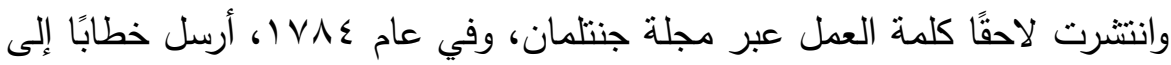

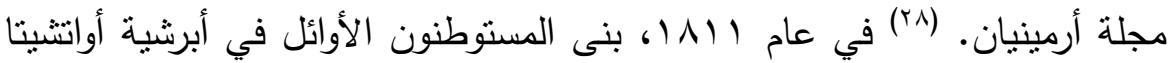
أول مدرسة لها أي سجل، على ضفاف نهر أواتشيتا من "الأخشاب الجيدة والبناء وعلى ارتفاع قدمين أو ثلاثة أقدام من الأرض". ربما تم تتفيذ التعليم في وقت سابق في فورت ميرو، الذي أصبح فيما بعد معروفًا باسم مونرو، لكهنة الفترة الاستعمارية المعينين في المركز التجاري الذين تم تكليفهم بتعليم القراءة والكتابة إلى جانب مسؤولياتهم الكتابية. على أي حال، كان هذا المبنى ذو الإطار الخشبي الفردي في أوقات الرواد هو رائد المدارس العشرين في نظام مدارس مدينة مونرو و بr مدرسة في نظام مدارس أواتشيتا باريش. (ror) في القرن التاسع عثر، رعت كنيسة إنجلترا معظم التعليم الرسمي حتى أنشأت الحكومة التعليم المجاني والإلزامي في نهاية ذللك القرن. تأسست University College London كأول كلية علمانية في إنجلترا قبل القرن التاسع عشر، كان هناك عدد قليل من المدارس. معظم تلك الموجودة كانت تدار من قبل سلطات الكنيسة وشددت على التعليم الديني. قاومت كنيسة إنجلترا المحاولات المبكرة للدولة لتوفير التعليم العلماني. في عام ال11، تم إنشاء

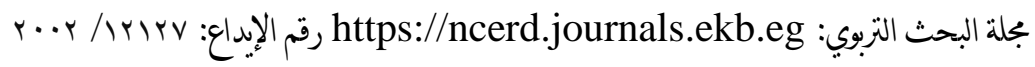

E-ISSN : r

ISSN: $\cdot \Lambda \Lambda r-I T \Lambda V$ 


$$
\text { السنت العشنى }
$$

الجمعية الأنجليكانية الوطنية لتعزيز تعليم الفقراء في مبادئ الكنيسة المؤسسة في إنجلترا ووبلز. المدارس التي أسستها الجمعية الوطنية كانت تسمى المدارس التهرئه الوطنية. تم استيعاب معظم المدارس الباقية في نهاية المطاف في نظام الدولة بموجب قانون بتلر (ع 9 (1)، وحتى يومنا هذا، تحافظ العديد من المدارس

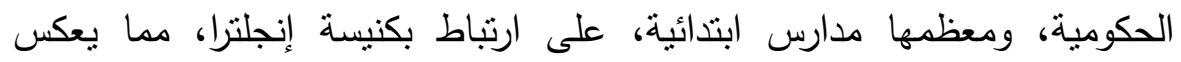

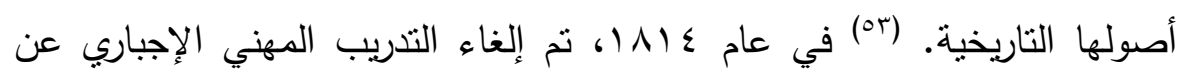
طريق السند. بحلول عام ابه ا، كانت مدرسة الأحد في بريطانيا العظمى تقدم

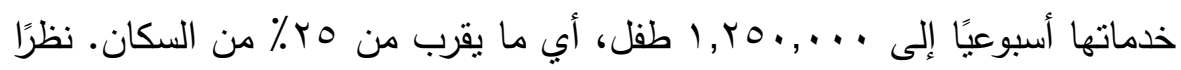
لأن هذه المدارس سبقت أول تمويل حكومي للمدارس لعامة الجمهور، يُنظر إليها

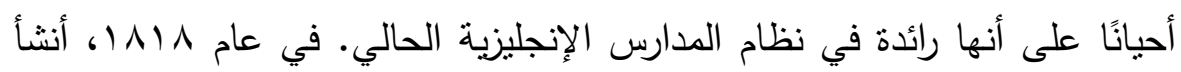
جون باوندز، المعروف باسم الإسكافي المقعد، مدرسة وبدأ بتعليم الأطفال الفقراء

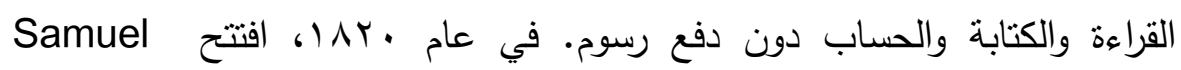
Wilderspin ويعتقل معظم المعلمين ان وجود طلاب من مختلف الأعمار والموظفين في نفس الغرفة يعوق العملية التعليمية والتدريس الجيد الاختلافات أهم من أوجه التشابه لم يكن هناك ما يثير القلق بثأن المدارس الصغيرة أكثر من منظمتهم "غير المصنفة". يعتقد معظم التريويين أن وجود طلاب من مختلف الأعمار والقدرات في هن هن نفس الغرفة يحول دون التدريس الجيد. كيف يمكن لمعلم واحد أن يقدم تعليمات متماسكة للطلاب المتباعدة في الإعداد الأكاديمي؟ قد يبتكر المعلمون الأذكياء تابير مؤقتة والارتجال بشكل مثير للإعجاب، لكنهم واجهوا مهمة مستحيلة بشكل أساسي عندما كان هناتك الكثير من التنوع في غرفة واحدة، فما شاركه الطلابأحياء متشابهة وأقارب مشتركون وتجارب مماثلة في المزرعة- كان أقل أهمية

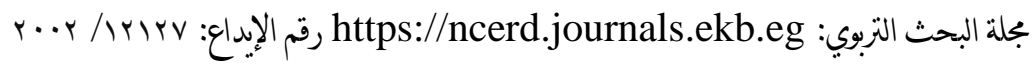

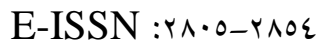

ISSN: $\cdot \wedge \wedge \mu-17 \wedge v$ 


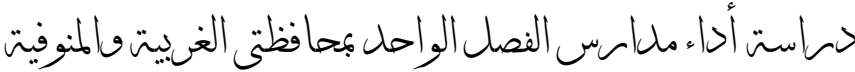

من اختلافاتهم. يجب فصل الطلاب حسب العمر • بدت المدرسة الصغيرة غير قادرة

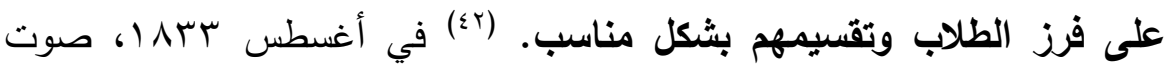

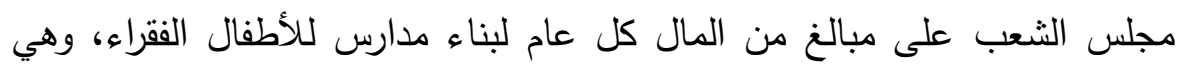

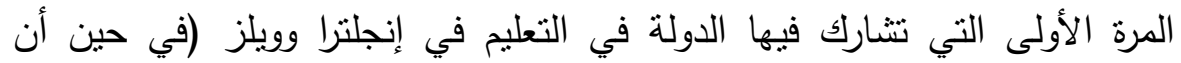

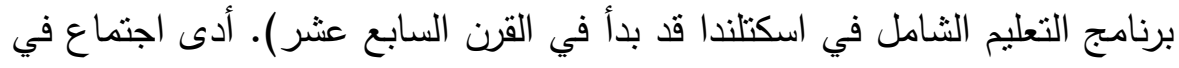
مانثستر عام VT/1، برئاسة مارك فيلييس، إلى إنثاء جمعية مدارس لانكثاير العامة. اقترحت الجمعية أن بتم تمويل المدارس غبر الطائفية من الضرائب المحلية.

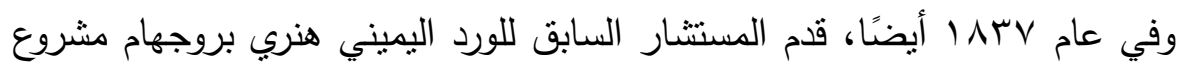

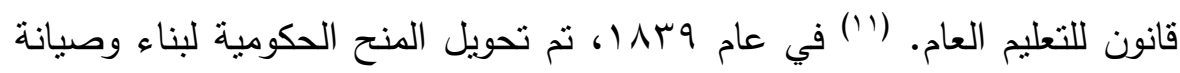

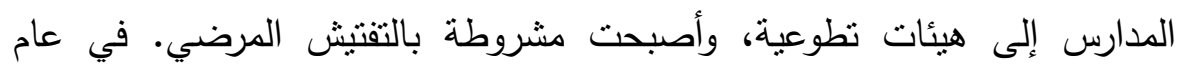

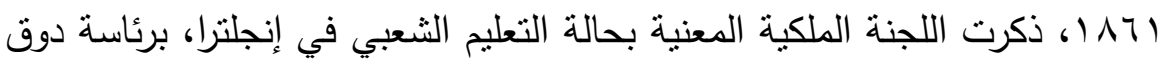

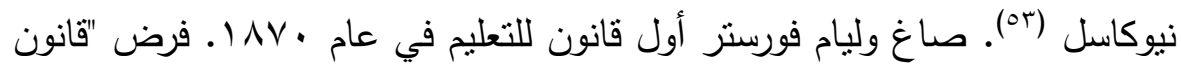

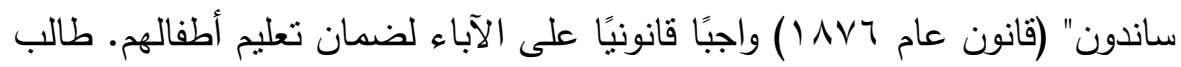

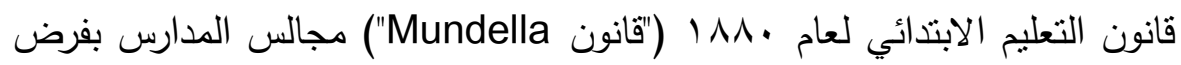

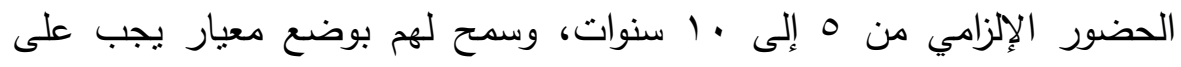

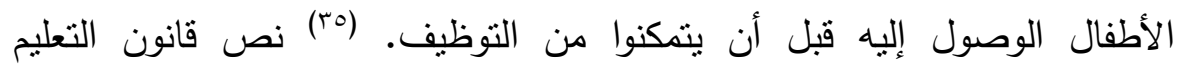

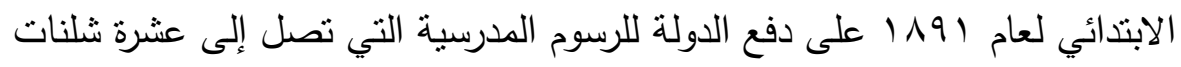

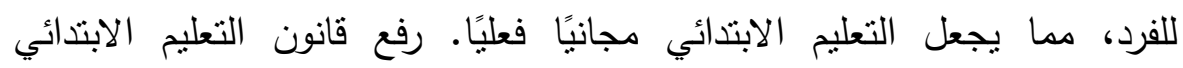

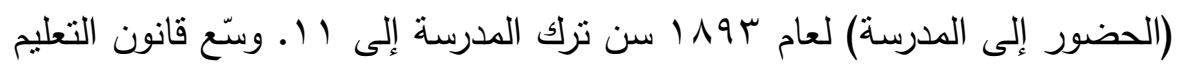
الابتدائي (الأطفال المكفوفون والصم) للعام نفسه التعليم الإلزامي للأطفال المكفوفين الكاني

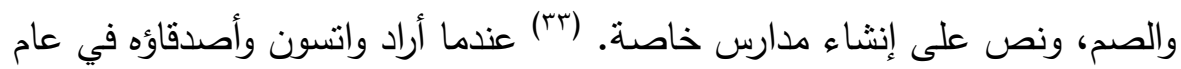

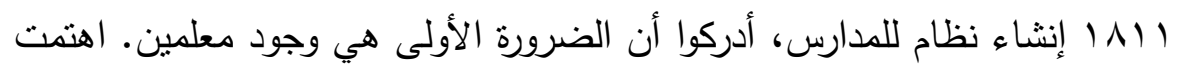

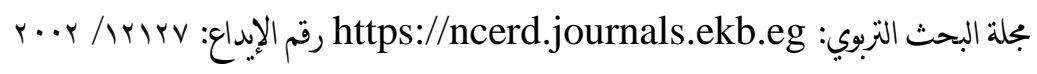

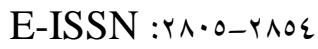
ISSN: $\cdot \Lambda \Lambda r-I T \Lambda V$ 
السنتالعشیون

الجمعية خلال سنتيها بتدريب المعلمين، بدءًا في توفير مدرسة مركزية. أدى ظهور التعليم الابتدائي الإلزامي عبر النظام المزدوج للمدارس التطوعية إلى جانب المدارس الخاضعة للسيطرة المحلية إلى مناقثات معقدة حول التعليم الديني في النظام الوطني. كان النظام المزدوج منافسًا بطبيعته وولد مشاكل تمويل متزايدة للمدارس التطوعية. رفع إمكانية التعليم المجاني للجميع من خلال المساعدة على الأسعار، كما ولّد مخاوف من أن تفقد الكنيسة حقها في تعيين المعلمين وأن الآباء سيفقدون حقوقهم في تعليم أطفالهم في سياق أنجليكاني. كما أدت الضغوط المالية إلى زيادة

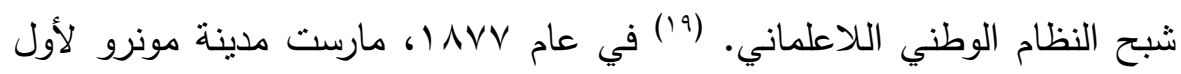
مرة سلطة ميثاقها لعام • ب 1 الذي يمنح البلدية الحق في إقامة وامتلاك مدارس. مرت المدينة بذخيرة لإنشاء نظام مدرسة مونرو، وفي عام ، 11، استحوذت على الى

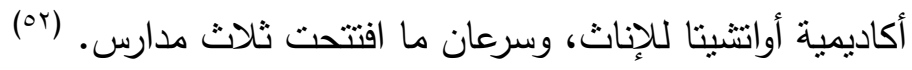
مدارس الفصل الواحد الانجليزية: بدأ حجم المدارس في المدن والضواحي أقل اعتراضًا عليها من المدارس في الريف الأمريكي. انقرضت المدارس الحضرية الصغيرة بحلول عام . .91، ونادرًا ما عادت للظهور • لم يكن التوسع في الحجم (خاصة في الضواحي) في المدارس الابتدائية الضخمة أو في عدد قليل من المدارس الثانوية الضخمة؛ لم تكن هذه شائعة جدًا. حد النموذج المثالي لـ "مدرسة الجوار الابتدائية" حجم المدارس الابتدائية

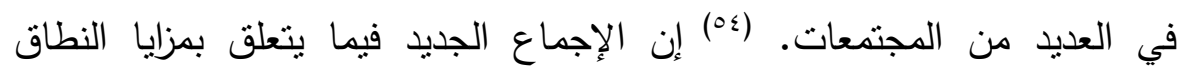
الصغير يذكرنا بأن التغيير الكبير في التعليم العام ممكن، كما يشير السيد هامبل. لا يبقى كل شيء على حاله من جيل إلى جيل. كانت المدارس الصغيرة في كل مكان. على الرغم من انخفاض عددهم بشكل مطرد مع ارتفاع معدلات تسجيل الطلاب، فقد ظلوا دائمين لفترة طويلة في معظم أنحاء البلاد. قائمة في عام

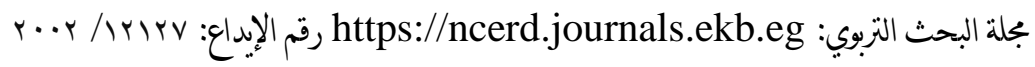

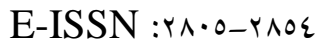

ISSN: $\cdot \wedge \Lambda \mu-17 \wedge V$ 


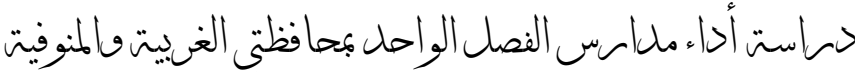

• 9 1، كان هناك . . . 11 مدرسة من غرفة واحدة، معظمها ابتدائية. أقل من

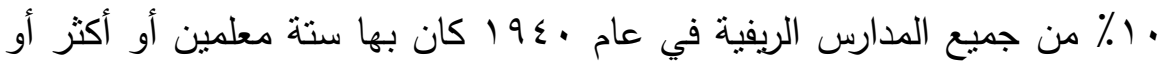
أكثر من . . . طالب. (rr) أنفق كونانت ومعظم المعلمين الأمريكيين الآخرين طاقاتهم في مهاجمة المدارس الصغيرة جدًا أكثر مما كرسوه لتأسيس الحجم الأمتل لمدرسة جيدة. كانت المشكلة التي يجب حلها هي سلسلة من المدارس الصغيرة، وكان أسلوب الهجوم هو التركيز على أوجه القصور في الصغر، وتجنب المهمة الأصعب المتمنلة في تحديد وتعزيز الحجم المثالي أو حتى النطاق. لم تكن المنطقة التي بدت فيها المدرسة الصغيرة غير كافية على الإطلاق هي توفير مساحة غرفة صف عادية. إن قلة الغرف المتخصصة، من ناحية، وغياب الغرف الكبيرة متعددة الأغراض، من ناحية أخرى، كان بنظر إلبها على أنها مشاكل لا يمكن التغلب عليها. يمكن أن توفر المدرسة الكبيرة بسهولة أكبر مساحة ومعدات للدورات المهنية (خاصة التدبير المنزلي للفتيات ومتاجر مختلفة للبنين). يمكن تدريس الفن والموسيقى والدراما في المدارس الصغيرة، لكن المباني افتقرت إلى مساحة كافية للتخزين والعروض. تتطلب ألعاب القوى، وهي الجزء الأسرع نموًا في المناهج الدراسية خلال زيادة الالتحاق في الثلاثثينيات، مساحة واسعة في الأبواب والأبواب

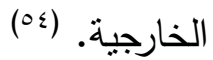

حاز مبنى المدرسة الكبير على الاحترام ليس فقط لمجموعة الغرف بالداخل. على النقيض من ذلك، فإن المدارس الريفية الأكثر رثابة، مثل تلاك التي تم تحويلها من الحظائر ومحلات البقالة وغرف البلياردو ومصانع الجبن وحظائر الأغنام، قد تكون على ما يبدو مشاهد مألوفة. (^) من المفترض أن المدارس الصغيرة لا تشتطيع تقديم عوامل جذب مهنية أكبر في المدرسة والمنطقة. كانت فرصة التخصص في مادة واحدة نادرة في المدرسة الصغيرة. (بr) داخل المدارس من جميع الأحجام،

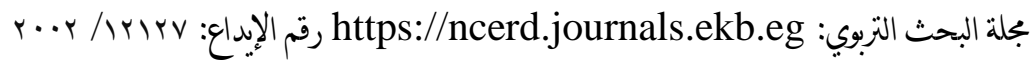

E-ISSN : r

ISSN: $\cdot \Lambda \Lambda r-I 7 A V$ 


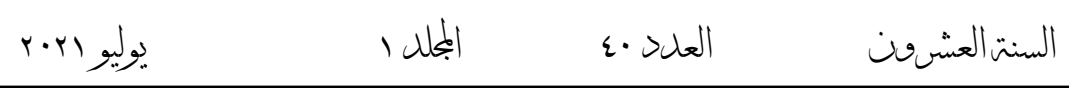

كانت هناك فصول دراسية، وبدت متثابهة بثكل ملحوظ من مدرسة إلى أخرى

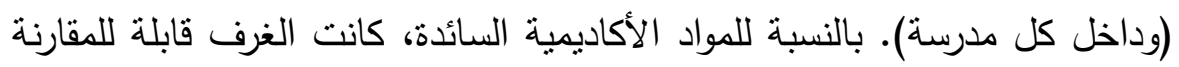

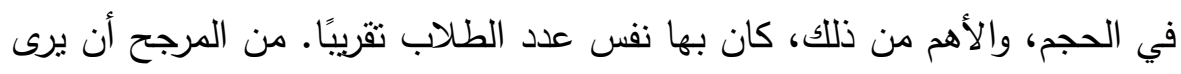

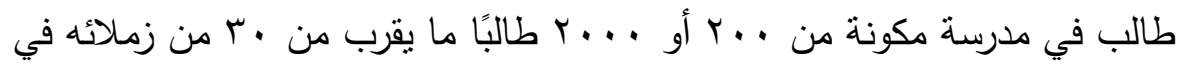

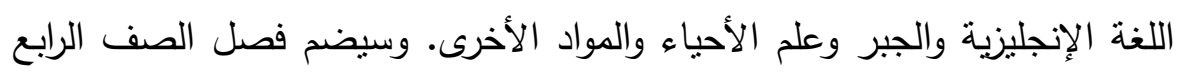

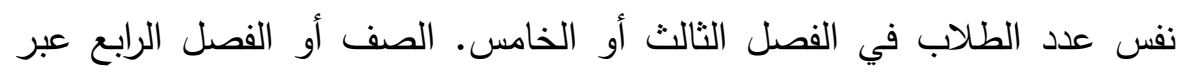

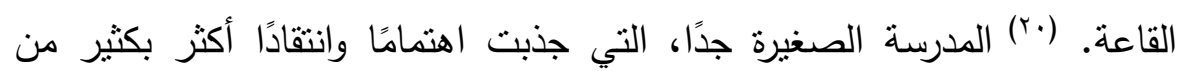

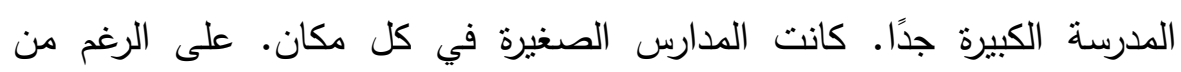

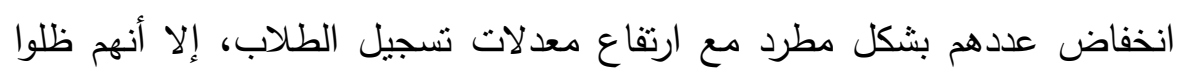

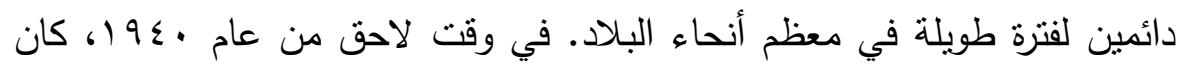

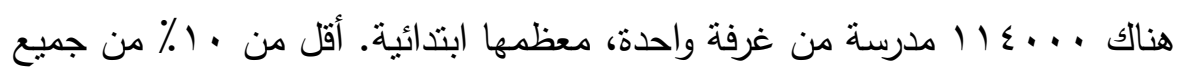

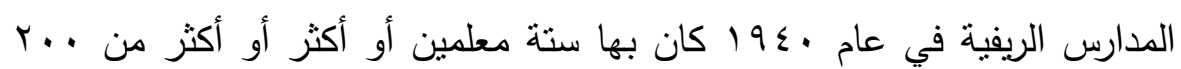

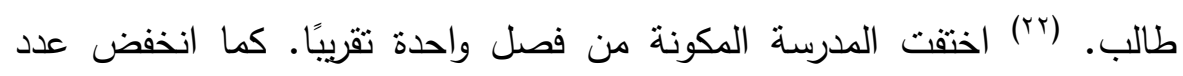

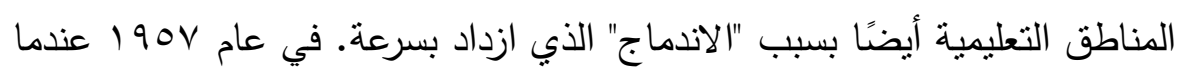

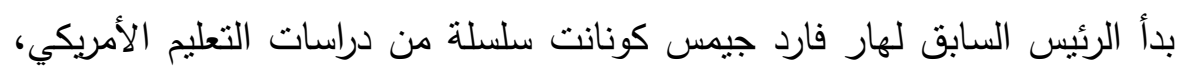

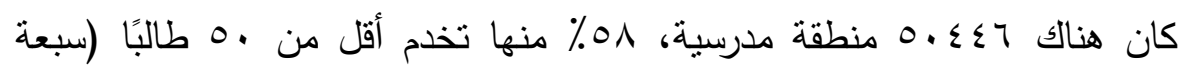

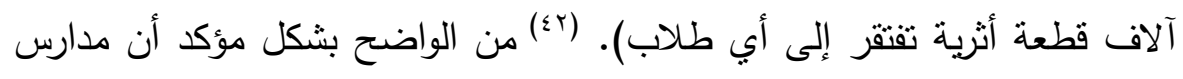

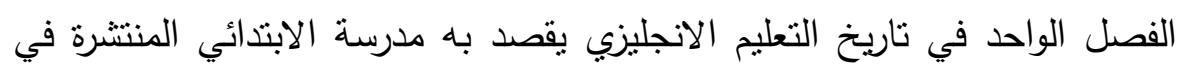

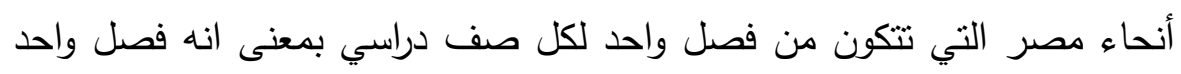

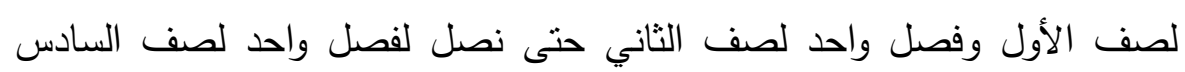

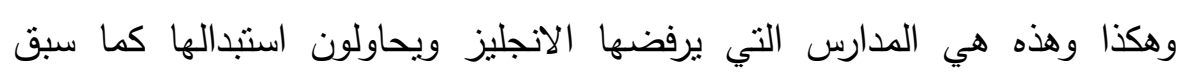

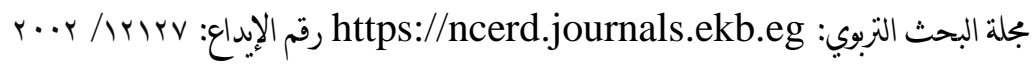

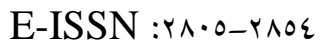

ISSN: $\cdot \wedge \Lambda \mu-17 \wedge V$ 


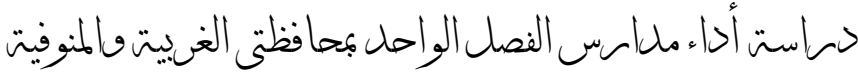

\section{الادراسة التطيقية}

أولاً: منهج الدراسة: يتبع هذا البحث الدنهج الوصفيه التهي التحليلي التطبيقي. ثانيًا: حدود الاراسة: -الحدود المكانية: مديرية التربية والتعليم بمحافظة الغربية

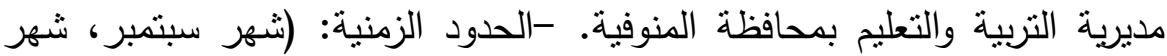

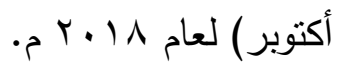

الإدارات التعليمية التابعة لمحافظة الغربية هم: -إدارة السنطة التعليمية - إدارة زفتى التعليمية- إدارة كفر الزيات التعليمية -إدارة بسيون التعليمية - إدارة قطور التعليمية - إدارة سمنود التعليمية -إدارة شرق المحلة النعليمية - إدارة غرب المحلة التعليمية - إدارة شرق طنطا التعليمية - إدارة غرب طنطا التعليمية. الإدارات التعليمية التابعة لمحافظة المنوفية هم: إدارة شبين الكوم التعليمية - إدارة

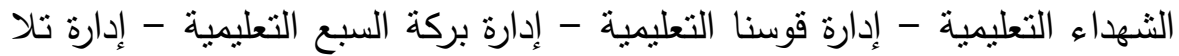

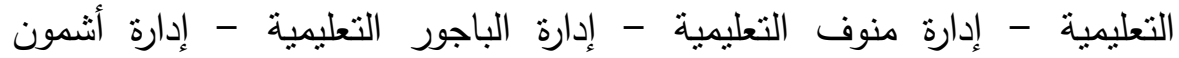
التعليمية- إدارة السادات التعليمية - إدارة سرس الليان التعليمية. وقد تم الذهب إلى الإدارات التعليمية ال •r التابعين للمديريتين التعليميتين

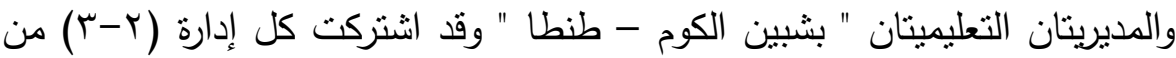
استمارات الاستبانة ولم تتشترك (ع) إدارات في مديرية التربية والتعليم في المنوفية لعدم وجود مدارس فصل واحد بهم. ورفض الاشتراك في البحث (V) وذللك لأسباب مختلف قد تم محاولة لتعرف عليها في الملاحظات المدرجة في جدول الذهاب للإدارات. بذلك تصبح عدد الإدارات المشتركة في البحث والمديرية (1) (1) من عدد

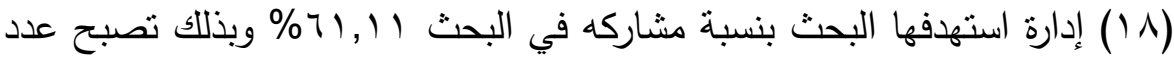

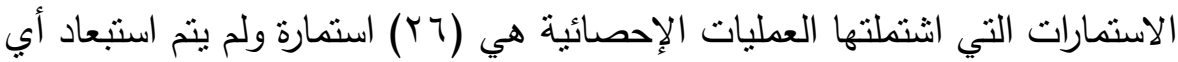
استمارة بسبب عدم استكمال البيانات حيث كانت الباحثة حريصة على استكمال

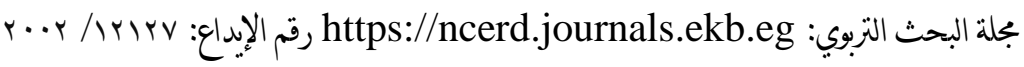
E-ISSN : r ISSN: $\cdot \Lambda \Lambda r-I T A V$ 


$$
\text { السنت العشقن }
$$

بيانات كل استمارة بشك دقيق غلى حد كبير . فتصبح عينة الدراسة (Tr) فردا وروعي في عملية الاختيار تمثيل العينة من مجتمع الدراسة من الموجهين الموجه لهم الاستبانة من العاملين في المديريتين التعليميتين.

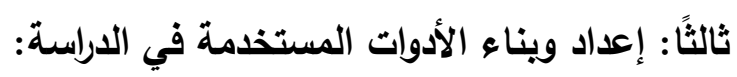
ا - إعداد وبناء استمارة جمع بيانات عامة.

r- استبانة موجة للموجهين في الإدارات التعليمية لمن أنشرف على مدارس الفصل الواحد أو على دراية بها وكون رأي عنها وقام بالإجابة على محاور

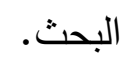

إعداد ويناء استمارة جمع بيانات عامة: - بيانات عن العاملين بالإدارات التعليمية - - الإدارة التعليمية التي يعمل بها. - - أعلى مؤهل دراسي حصل عليه. - - أقدمية العمل في الوظيفة.

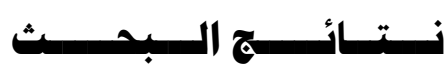

عينة البحث تضمنت عدد (1/) إدارة تعليمية والمديريتان التعليميتان الذين أثتركن في البحث عدد (11) ما يعادل ||, آ7\% من عينة البحث والباقي وعدده

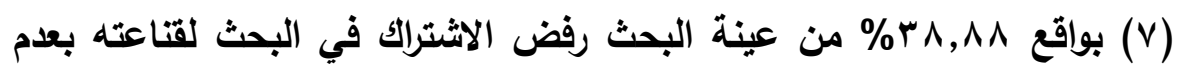
جدوى مدارس الفصل الواحد وأنها غير ذات جدوى ومضيعة للوقت والجها ولا يوجد لها أب مردود على العملية التعليمية.

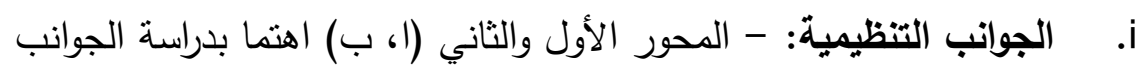
التتظيمية لمدارس التعليم المجتمعي (الفصل الواحد).

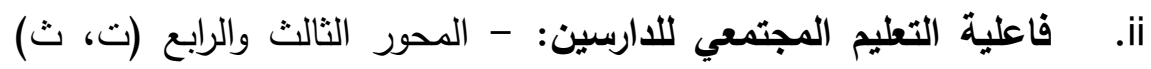
اهتما بدراسة فاعلية مدارس التعليم المجتمعي (الفصل الواحد).

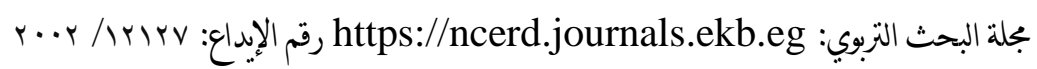

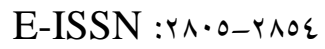
ISSN: $\cdot \wedge \Lambda \mu-17 \wedge \nu$ 


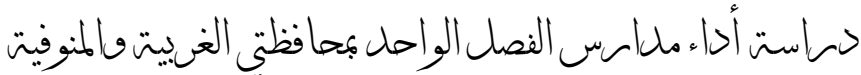

iii انتظام العملية التعليمية للعاملين: - المحور الخامس (ج) اهتم بدراسة انتظام العملية التعليمية داخل مدارس التعليم المجتمي (الفصل الواحد) اللعاملين فيها.

إعداد ويناء ومنظومة الاستبانة الخاص بمدارس التطليم المجتمعي: - تحديد الدخلات الخاصة بالعملية التعليمية /1 عبارة وتضمنت الجمل

$$
\text { (1)-1) }
$$

- تحديد العمليات الخاصة بالعملية التعليمية وهي 1 عبارات وتضمنت

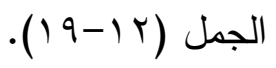

- تحديد المخرجات الخاصة بالعملية التعليمية وهي 1 عبارات وتضمنت

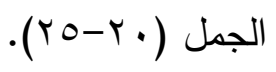

استبانة موجة للموجهين في الإدارات التعليمية لمن أشرف على مدارس الفصل الواحد أو على دراية بها وكون أي عنها وقام بالإجابة على محاور البحث: - المحور الأول وهو جذب الفئة المستهدفة " المتسربين من التعليم ومن فاتهم سن

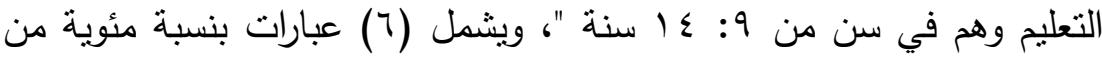
إجمالي أسئلة الاستبانة ا, وب\% وركزت الأسئلة على جذب الفئة المستهدفة " المتسربين من التعليم ومن فاتهم سن التعليم وهم في سن من 9: ـ ا سنة ". وإذا كانوا يحضرون ونسبة الحضور إذا كانت مقبولة أو غير مقبولة. - المحور الثاني وهو عدم تسرب الدارسين من مدارس الفصل الواحد " التعليم المجتمعي "، ويثمل (0) عبارات بنسبة مئوية من إجمالي أسئلة الاستبانة باץ,9 \% وركزت الأسئلة على مدى تسرب الدارسين من الفصل الواحد "

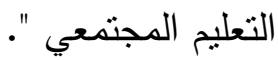

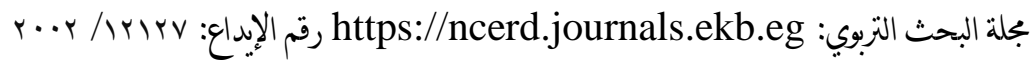

E-ISSN : r

ISSN: $\cdot \Lambda \Lambda r-I T A V$ 
السنترالعشنف

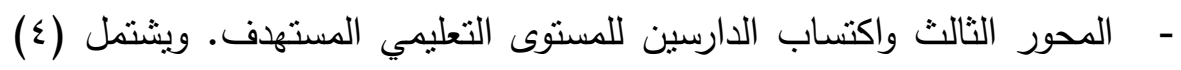

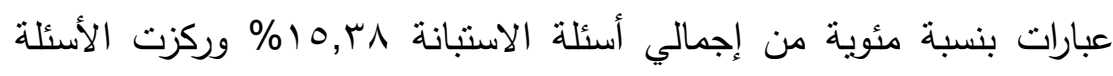

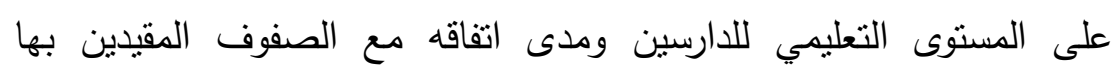
واكتساب الدارسين سلوكيات مقبولة من خلال العملية التعليمية. - المحور الرابع وهو اكتساب الدارسين مهارة يدوية تعينهم على العمل اكتسبوها من المدرسة، ويشتمل (ع) عبارات بنسبة مئوية من إجمالي أسئلة الاستبانة

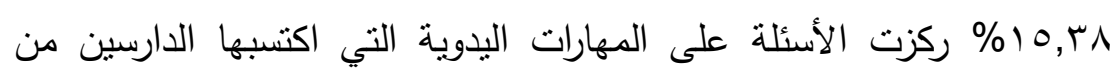
المدرسة والقدرات التسويقية التي اكتسبوها من المدرسة. - المحور الخامس وهو انتظام العملية التعليمية داخل مدرسة الفصل الواحد " التعليم المجتمعي " من قبل العاملين بالمدرسة. ويشمل (V) عبارات بنسبة دهاته

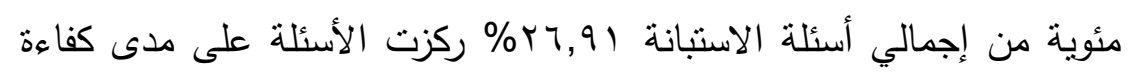
المدرسات (الميسرات) على تدريس المادة العلمية الموكلة إليهم والتحضير

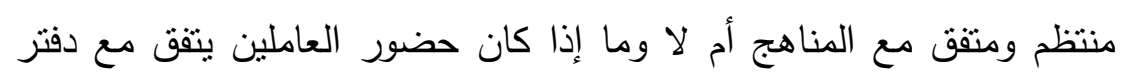
غياب المدرسة.

• وفي جميع المحاور يوجد خانة خاصة لكي يضع حضرات الموجة لهم

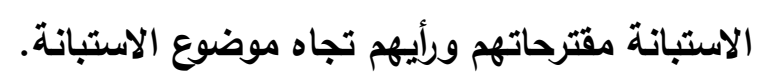

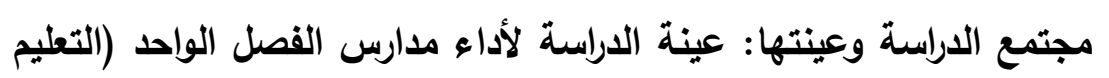
المجتمعي) تكون مجتمع الدراسة من العاملين في الإدارات التعليمية (موجهين أو القائمين بأعمال التوجيه ولديهم دراية تعليم مجتمعي " فصل واحد") بمحافظة الغربية والمنوفية لمن وجدت في إداراتهم تعليم مجتمعي (فصل

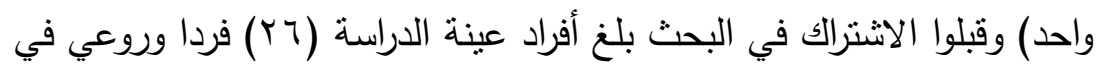
عملية الاختيار تمثيل العينة من مجتمع الدراسة من الموجهين العاملين في

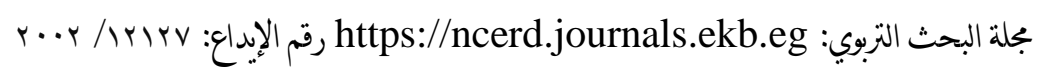

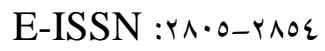

ISSN: $\cdot \wedge \Lambda \mu-17 \wedge V$ 


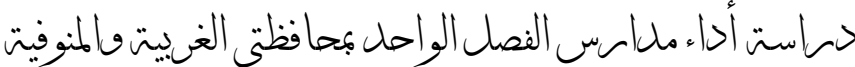

الإدارات التعليمية. وييين الجدول (r) توزيع أفراد العينة بحسب متغيرات

الدراسة.

جدول (Y): توزيع أفراد العينة حسب متغيرات الاراسة

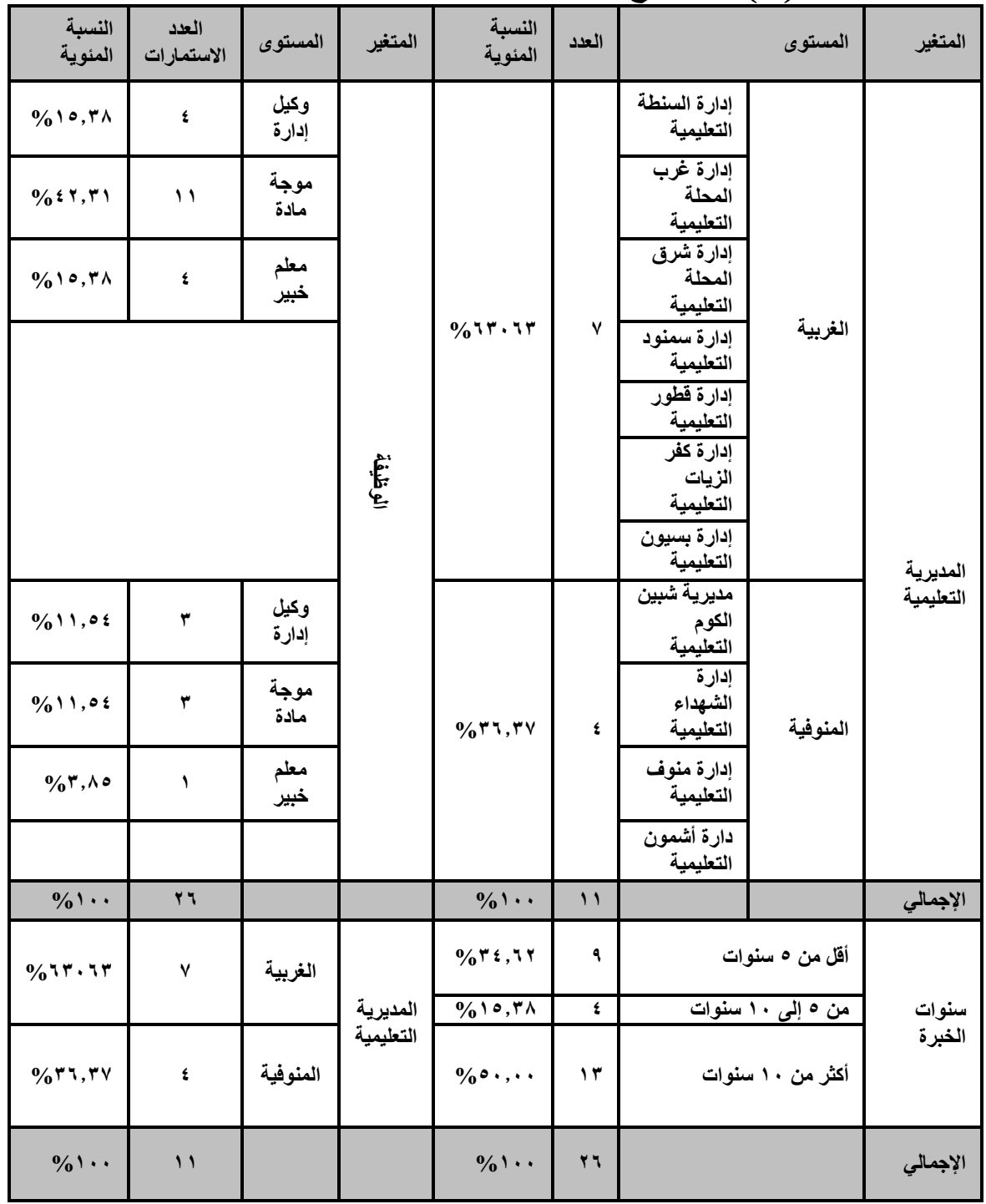

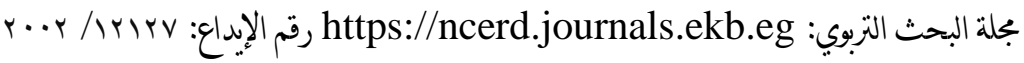

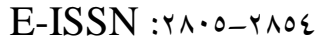

ISSN: $\cdot \Lambda \Lambda r-I 7 N V$ 
السنت العشنفن

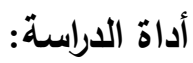

مقياس "أداء التعليم المجتمعي (الفصل الواحد)": لتحديد أداء التعليم المجتمي، استرشدت الباحثة ببعض الاستبانات المستخدمة في الدراسات السابقة لتحديد أهم المحاور والفقرات التي يجب أن تتضمنها الاستبانة وعرضت الاستبانة على أستاذ

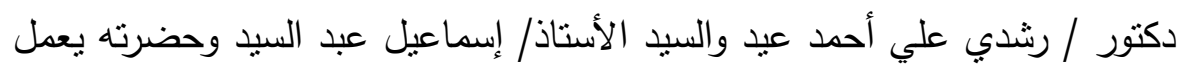
موجة رياضيات في إدارة الثهاء التحليمية بمديرية التربية والتعليم بالمنوفية والسيد/ موجة لغة عربية بإدارة منوف التعليمية بمديرية التربية والتعليم بالمنوفية وحضرته

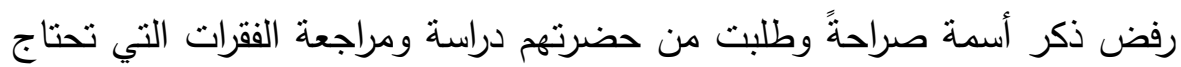
إلى تعديل أو إضافة وحذف الفقرات التي يرون أنها غير فاعلة أو صالحة ثم إعادة صياغة الفقرات التي تحتاج إلى تعديل أو إضافة لتتكون الاستبانة في صورتها النهائية من (YT) فقرة موزعة.

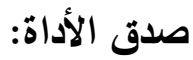
يعرف صدق (صلاحية) أداة القياس على إنه قدرة الأداة على قياس ما صممت من أجله وحيث أن اعتماد الباحث على منطقه الشخصي دليل غير كاف لصدق الأداة فقد نم التحقق من صدق الأداة باستخدام "صلاحية المحتوى" content validity وهي عبارة عن حكم شخصي مبنى على الربط المنطقي بين المفردات التي تحنويها

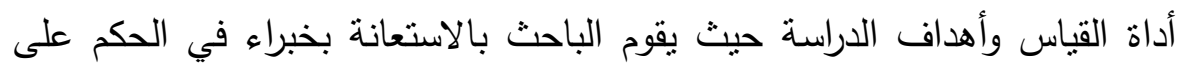
صلاحية المحتوى وذلك بالتأكد من أن أداة القياس تحتوي على مفردات تغطى بلى بلاهي الفكرة التي تدرس بالكامل وصلاحية تمثيل الفقرات للصفة المراد قياسها.

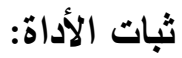

يقصد بالثبات الحصول على نفس القيم عند إعادة استعمال أداة القياس وبالنالي كلما ازدادت درجة الثبات واستقراره كلما ازدادت الثقة فيه وقد تم استخدام معادلة

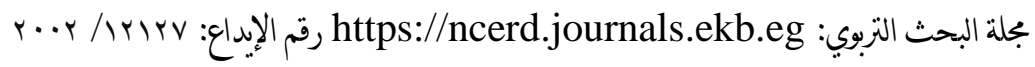

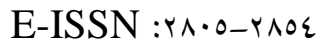

ISSN: $\cdot \wedge \Lambda \mu-17 \wedge V$ 


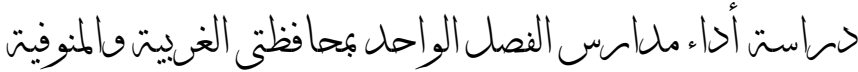

معامل ألفا-كرونباخ Cronbach's Alpha الثبات حيث بلغت قيمته (إكד، •) وهي قيمة تفي بأغراض الدراسة. جدول (r): معاملات الثبات للمحاور الرئيسية والفرعية لمقياس "فاعلية التعليم

\begin{tabular}{|c|c|c|c|}
\hline معامل الثبات & عدد المفردات & المحور & b \\
\hline \multirow[t]{2}{*}{$.6 V Y V$} & \multirow[t]{2}{*}{9} & 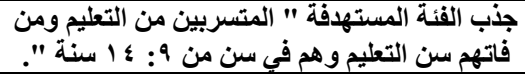 & \multirow{2}{*}{ 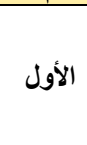 } \\
\hline & & للمحور & \\
\hline \multirow[t]{2}{*}{$.670 \mathrm{~V}$} & \multirow[t]{2}{*}{$\bullet$} & عدم تسرب الدارسين من مدارس الفصل الواحد " & \multirow[t]{2}{*}{ الثاني } \\
\hline & & للمحور & \\
\hline \multirow{2}{*}{ 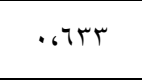 } & \multirow{2}{*}{$\varepsilon$} & اكتساب الادارسين للمستوى التعليمي المستهدف. & \multirow{2}{*}{ 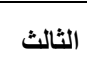 } \\
\hline & & للمحور & \\
\hline \multirow[t]{2}{*}{$.6 V Y \wedge$} & \multirow[t]{2}{*}{$\varepsilon$} & 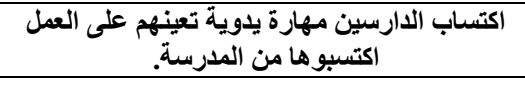 & \multirow{2}{*}{ 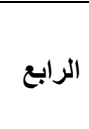 } \\
\hline & & ل للمحور & \\
\hline \multirow{2}{*}{$.6 V Y \wedge$} & \multirow{2}{*}{$\checkmark$} & انتظام العملية التعليمية داخل المدرسة للعاملين فيها & \multirow{2}{*}{ 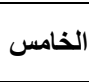 } \\
\hline & & للمحور & \\
\hline .6799 & $r q$ & معامل الثبات الكلى & \\
\hline
\end{tabular}

وقد قاموا الأساتذة بالمساهمة في: -تصحيح صياغة العبارات. - ملائمة العبارات للهدف منها. - مدى ارتباط العبارات بكل محور من محاور الاستبانة في ضوء التعريفات الإجرائية.

تحويل البيانات الوصفية إلى كمية: تم تحويل بيانات استمارة الاستبانة الوصفية إلى كمية عن طريق دليل لتحويل تلك البيانات الوصفية إلى قيمة بإعطاء قيمة لكل سؤال حسب إجابته الآتية: تقدير درجات الاستبانة باستخدام مفتاح تصحيح مندرج متصل، وفقًا لتناث استجابات وهي (نعم - إلى حد ما - لا) وتم التصحيح في بالي ضوء الأوزان المحددة للتقدير الثلاثي وهي نعم (r) وإلى حد ما (r) ولا ( () للعبارة.

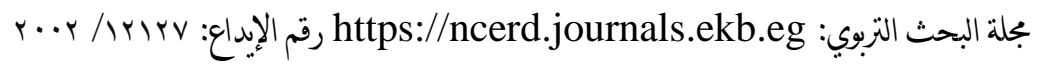

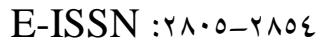

ISSN: $\cdot \Lambda \Lambda r-I T \Lambda V$

rT. 


$$
\text { السنت العشقن }
$$

i. الجواتب التنظيمية: - المحور الأول والثاني (ا، ب) اهتما بدراسة الجواتب التنظيمية لمدارس التعليم المجتمعي (الفصل الواحد).

فاعلية التعليم المجتمعي للدارسين: - ii اهتما بدراسة فاعلية مدارس التعليم المجتمعي (الفصل الواحد).

i أنتظام العملية التعليمية للعاملين: - المحور الخامس (ج) اهتم بدراسة انتظام العملية التعليمية داخل مدارس التعليم المجتمعي (الفصل الواحد) للعاملين فيها.

أولا: - إحصاء لعينة البحث كاملة بإغفال المتغيرات لكل محاور البحث أ إحصاء الجوانب التنظيمية:

جدول (ء): المتوسطات الحسابية والانحرافات المعيارية ونتائج اختبار(ت) لعينة البحث كاملة بإغفال المتغيرات (للمحور الأول والثاني)"الجوانب التنظيمية

\begin{tabular}{|c|c|c|c|c|c|c|c|c|}
\hline \multirow[b]{2}{*}{ الاختبار } & \multirow{2}{*}{ الاتجاه } & \multirow[b]{2}{*}{ الدلالة } & \multicolumn{2}{|c|}{ فترة الثقة } & \multirow[b]{2}{*}{ المعياري } & \multirow[b]{2}{*}{ المتوسط } & \multirow[b]{2}{*}{ المجموع } & \multirow[b]{2}{*}{ المحاور } \\
\hline & & & الأقصى الحد & الأدنى & & & & \\
\hline$\cdot, \cdots$ & موجبة & $\cdot, \cdots 1$ & 10,717 & 17,791 & $\cdot, \vee \vee १ ४$ & $r, \leqslant \curlyvee \wedge$ &.$r \wedge \theta$ & الأحول \\
\hline ס r, & موجبة & $\cdot, \cdots 1$ & 11,YTY & $9, Y q r$ & $\cdot, V Y I$ & $r, 1$ &.$r V r$ & الثاني \\
\hline
\end{tabular}

الإحصاءات الوصفية المتوسطات الحسابية والانحرافات المعيارية ونتائج اختبار(ت) لعينة البحث كاملة بإغفال المتغيرات (للمحور الأول والثاني) "الجوانب التنظيمية" تم استخراج المتوسطات الحسابية والانحرافات المعيارية كما تم استخدم اختبار (ت) لتحديد فترة الثقة في العينة الواحدة.

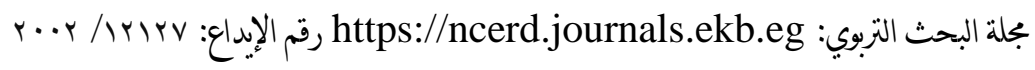

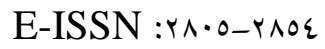

ISSN: $\cdot \wedge \Lambda \mu-17 \wedge V$ 


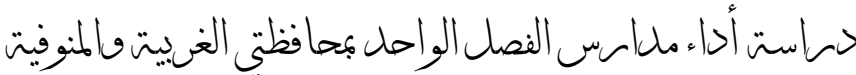

حيث يتضح من الجدول الخاص بالجوانب التظظيمية أن الفصل الواحد قادر على جذب الفئة المستهدفة أكثر من عدم نسرب الدارسين منة وذللك بالمقارنة بين المتوسطين الحسابيين للحور الأول جذب الطلبة والمحور الثاني عدم تسرب الثبن

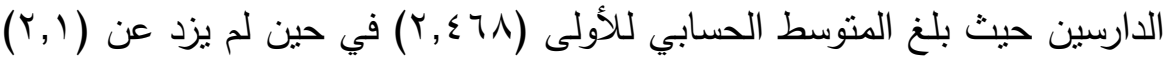

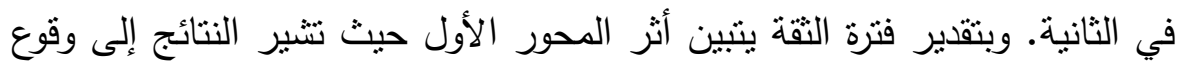

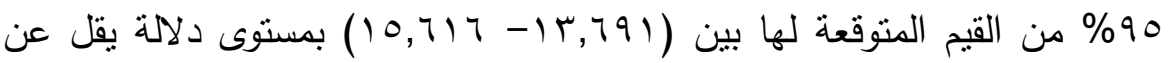

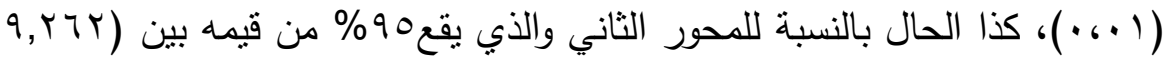

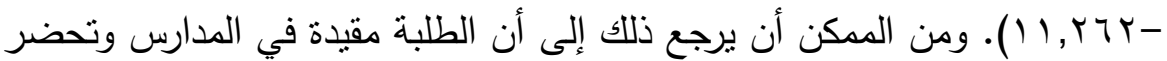

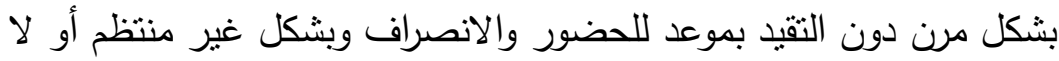
تحضر للمدرسة ويكتفى بأنهم مسجلين بها فقط وبالرغم من نتائج المحور الأول

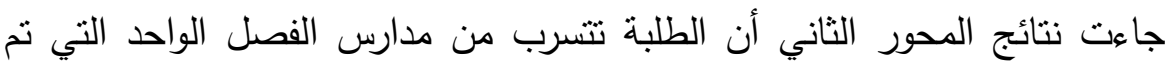
إنشاؤه لحل مشكلة تسرب الطلبة. ونتائج اختبار (ت) جاءت بدلالة بين المحور الثاني والأول مما يدل على أن هناك لكأك

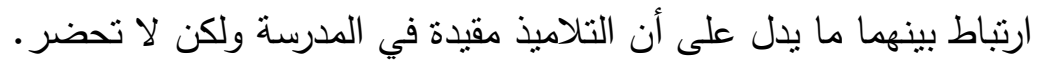

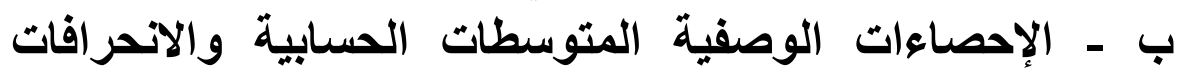

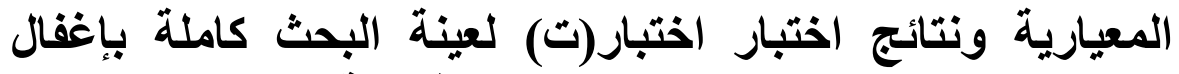

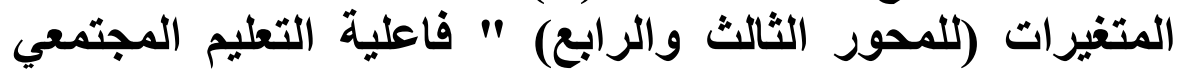

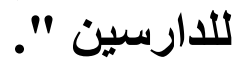

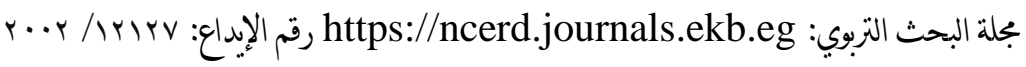

E-ISSN : r

ISSN: $\cdot \Lambda \Lambda r-I T A V$ 
السنتشالعشن

جدول (0): المتوسطات الحسابية والانحرافات المعيارية ونتائج اختبار(ت) لفاعلية مدارس الفصل الواحد (التعليم المجتمعي)

\begin{tabular}{|c|c|c|c|c|c|c|c|c|}
\hline \multirow[b]{2}{*}{ الاختبار } & \multirow[b]{2}{*}{ الاتجاه } & \multirow[b]{2}{*}{ مستوى الدلالة } & \multicolumn{2}{|c|}{ فترة الثقة } & \multirow[b]{2}{*}{ لالمعراف } & \multirow[b]{2}{*}{ المتوسط } & \multirow[b]{2}{*}{ المجموع } & \multirow[b]{2}{*}{ المحاور } \\
\hline & & & الأقصى الحد & الأدنى الحـ & & & & \\
\hline$r \Delta, r \vee T$ & موجبة &,,$\ldots$ & $11, \mathrm{~V} \vee \mathrm{r}$ & $9,1 \leq 9$ & $\cdot, V Y I$ & $r, \theta$ & . & الثالث \\
\hline $\mid r, \varepsilon \leqslant \varepsilon$ & موجبة & $\cdot, \ldots$ & $q, \leqslant 14$ & $\checkmark, \vee \leqslant$. & $\cdot, \wedge \wedge \wedge$ & $r, \ldots$ &.$r \cdot \Lambda$ & الرابع \\
\hline
\end{tabular}

حيث يتضح من الجدول الخاص بفاعلية التعليم بالفصل الواحد للمتعلمين نجد أن المحور الثالث الذي يقيس اكتساب الدارسين للمستوى التعليمي المستهدف تأثنره أكبر مقارنة بالمحور الرابع الذي يقيس اكتساب الدارسين لمهارة يدوية وتسويقها ذلك بالمقارنة بين المتوسطين الحسابيين للمحور الثالث كتساب الدارسين للمستوى التعليمي المستهفف والمحور الرابع لذي يقيس اكتساب الدارسين لمهارة يدوية

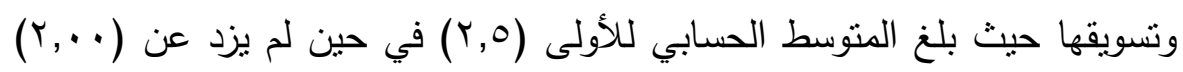

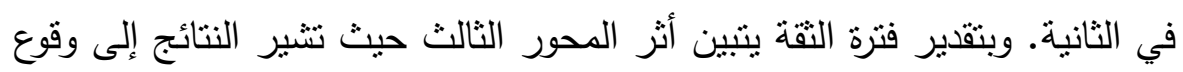

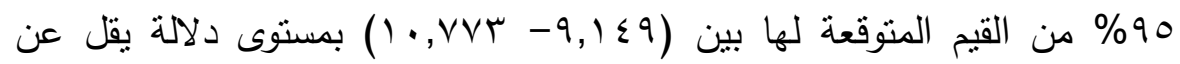

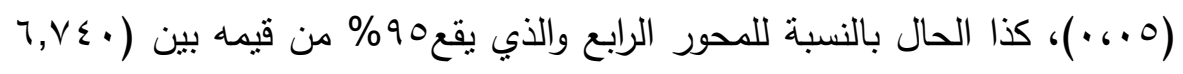
- ب (؟,9). ومن الممكن أن يرجع ذللك إلى أن الطلبة التي تحضر تتعلم القراءة والكتابة قدر المسنطاع ولا يوجد اهتمام كافي بمواد التكوين المهني والمشروعات

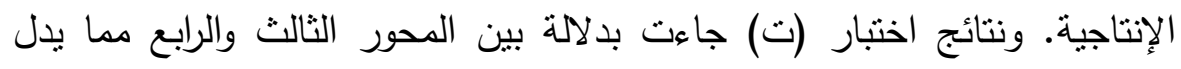

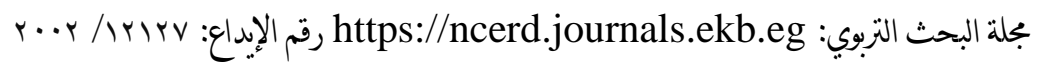

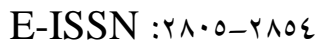

ISSN: $\cdot \wedge \Lambda \mu-17 \wedge V$ 


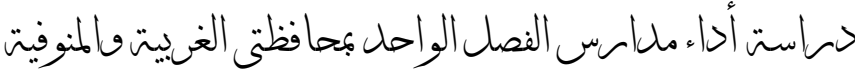

على أن هناك ارتباط كبير بين المحورين لصالح المحور الثالث ما يدل على أن التلاميذ تتعلم القراءة والكتابة أكثر من الحرف اليدوية. ت -الإحصاءات الوصفية المتوسطات الحسابية والانحرافات المعيارية ونتائج اختبار (ت) لعينة البحث كاملة بإغفال المتغيرات (للمحور الخامس).

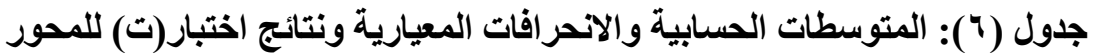

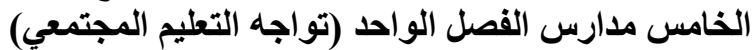

\begin{tabular}{|c|c|c|c|c|c|c|}
\hline الاختبار & الأقصى الحد & الأدنى & المعياري & المتوسط & المجموع & الأسئلة \\
\hline \multirow{7}{*}{.,$r \leqslant 9 \wedge$} & \multirow{7}{*}{$r$} & \multirow{7}{*}{ •,Orr } & 0.421325 & 2.769231 & 72 & س ·r \\
\hline & & & 0.689095 & 2.576923 & 67 & س س \\
\hline & & & 0.556032 & 2.807692 & 73 & س Yr \\
\hline & & & 0.616585 & 2.653846 & 69 & س سTr \\
\hline & & & 0.73782 & 2.384615 & 62 & س \\
\hline & & & 0.785407 & 2.192308 & 57 & س W \\
\hline & & & 0.523133 & 2.730769 & 71 & س ry \\
\hline
\end{tabular}

حيث يتضح من الجدول الخاص بانتظام العملية التعليمة للعاملين بالفصل الواحد والذي تمثل في المحور الخامس نجد أن السؤال ال • r الذي قاس الثرح الجيد لمدرسة الصف الأول والثاني والثالث أكبر بالمقارنة بالسؤال اب الذي قاس الثرح الجيد لمدرسة الصفوف الرابع والخامس والسادس وذللك بالمقارنة بين المنوسطين الحسابيين للسؤالين حيث بلغ المتوسط الحسابي للأولى (Y,V79) في حين الثاني لم

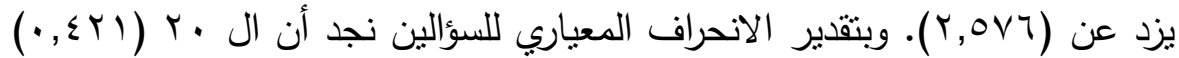

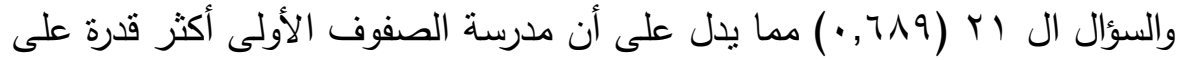
توصيل المعلومة مقارنة بمدرسة الصفوف الأعلى وذللك يوضح رأي من طبق عليهم الاستبانة بعدم قدرة مدرسة الصفوف العليا على توصيل المعلومة بنفس كفاءة المدرسين المتخصصين في مدارس الابتدائي العام.

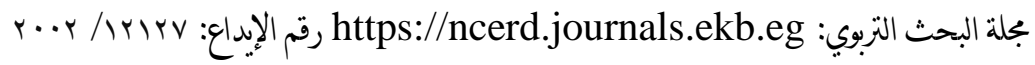

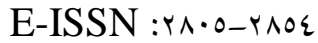

ISSN: $\cdot \Lambda \Lambda r-I T \Lambda V$ 


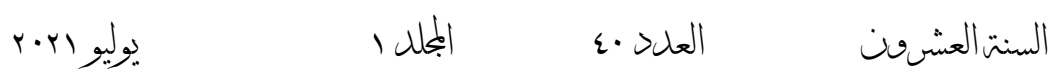

ونجد أن السؤال ال بr الذي قاس قيام الدرسات بالتحضير بشكل منظظم أكبر بالمقارنة بالسؤال بr الذي قاس إنهاء المنهج لجميع المواد في وقت مناسب للعملية التعليمية وذلك بالمقارنة بين المتوسطين الحسابيين للسؤالين حيث بلغ المتوسط

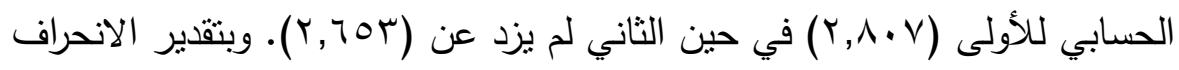

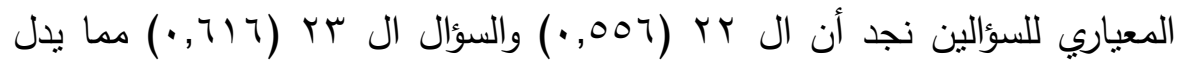
على ان الددرسات يقمن بالتحضبر بشكل منتظم ولكن هناك صعوبة في إنهاء الناهج بشكل يتفق والعملية التعليمية ومن المككن ان يدل ذللك على الصعوبة التي

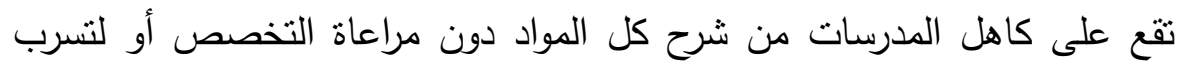
الدارسين من مدارس الفصل الواحد.

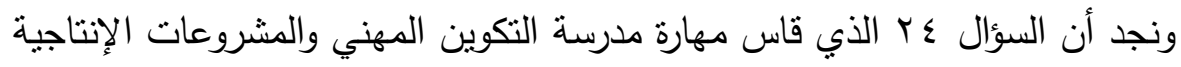

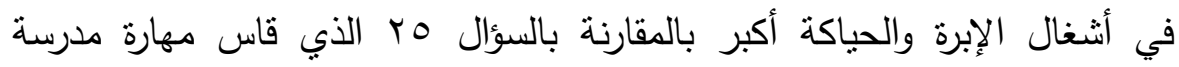
التكوين المهني والمشروعات الإنتاجية في المجال الزراعي والصناعي والسباكة

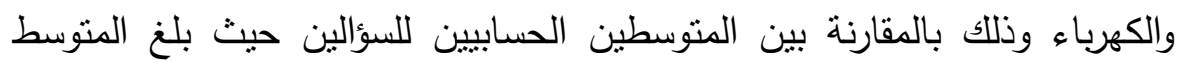

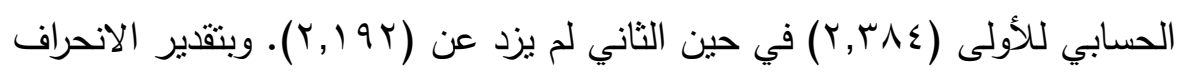

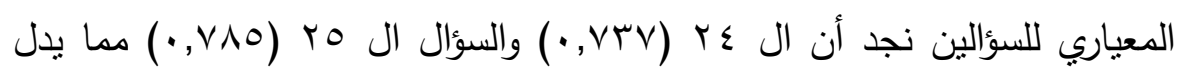

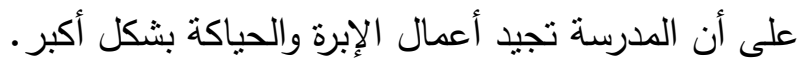

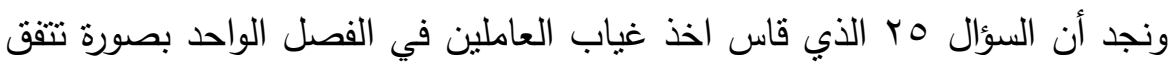

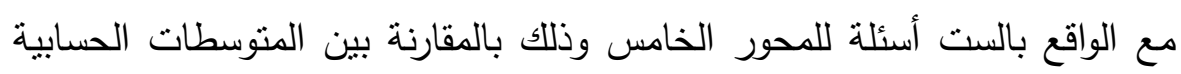

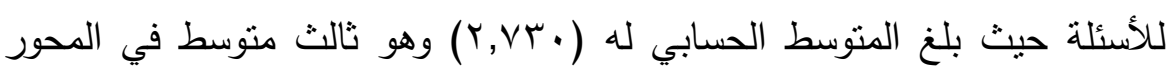
حين الخامس مما يدل على أن المدرسة تأخذ الغياب للعاملين بشكل مرن.

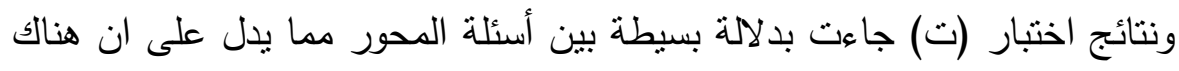
ارتباط بسيط بين أسئلة البحث ما يدل على ان انتظام العملية التعليمية داخل مدرسة

بحلة البحث الزبوي: https://ncerd.journals.ekb.eg رقم الإداع:

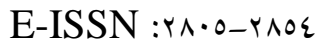

ISSN: $\cdot A \Lambda Y-I T A V$ 


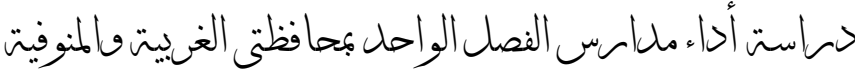

الفصل الواحد " التعليم المجتمعي " من قبل العاملين بالمدرسة لها ما لها وعليها ما عليها كما ذكر الموجهين في الملاحظات. ثانيًا: - الإحصاء لمتغير الوظيفة الإحصاءات الوصفية:

تم استخراج المتوسطات الحسابية والانحرافات المعيارية للمحاور الخمسة تبعًا لمتغير الوظيفة. جدول (V): المتوسطات الحسابية والانحرافات المعيارية لمتغير الوظيفة لمدارس الفصل الواحد (التعليم المجتمعي) المونطي)

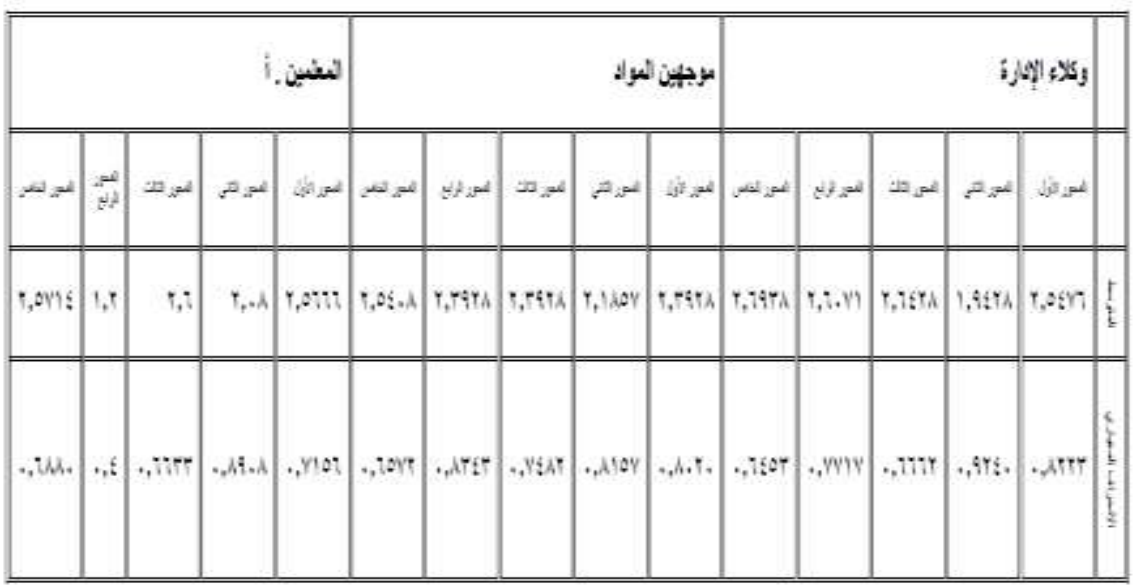

حيث يتضح من الجدول الخاص المتوسطات الحسابية والانحراف المعياري لمتغير الوظيفة (وكلاء الإدارة - موجهين المواد - المعلمين أ العاملين بالإدارة) نجد انه عند مقارنة المتوسطات الحسابية في المحور الأول نجد أن أعلى متوسط فيه

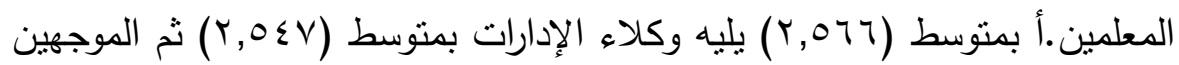

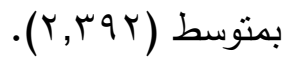

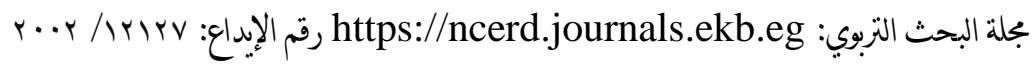

E-ISSN : r

ISSN: $\cdot \Lambda \Lambda r-I 7 A V$ 
السنت العشنف

ونجد انه عند مقارنة المتوسطات الحسابية في المحور الثاني نجد أن أعلى متوسط

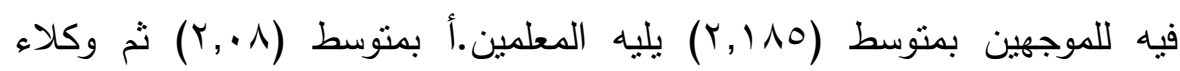
الإدارات بمتوسط (r 9 (1) ).

ونجد انه عند مقارنة المتوسطات الحسابية في المحور الثالث نجد أن أعلى متوسط

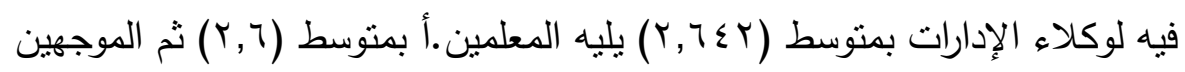
بمتوسط (r ب r, (1) ).

ونجد انه عند مقارنة المتوسطات الحسابية في المحور الرابع نجد أن أعلى متوسط

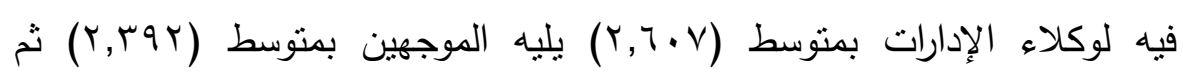

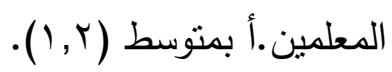

ونجد انه عند مقارنة المتوسطات الحسابية في المحور الخامس نجد أن أعلى

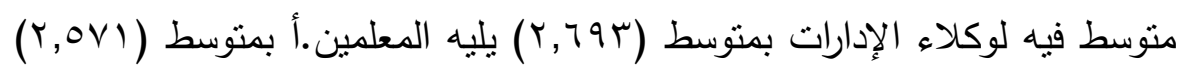

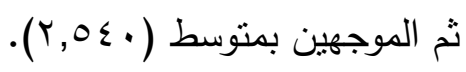

حيث يتضح من الجدول الخاص بالمقارنة بين جميع المحاور تبعًا لمتغير الوظيفة بالمقارنة بين المتوسطات الحسابية لكل محور بمثيلة في المجموعات الوظيفية الثلاثة (وكلاء الإدارة - موجهين المواد - المعلمين أ العاملين بالإدارة) نجد أن

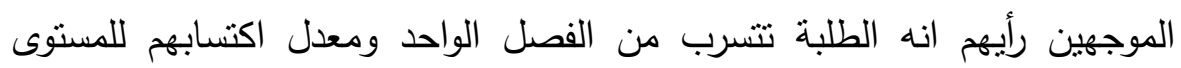
التعليمي والحرفي المستهدف أقل مما يسعون له وهذا يتفق مع رأيهم الذي كتبوه من قبل في خانة الملاحظات بالاستبانة بان الطلبة المقيدين بالمدرسة والذين يحضرون

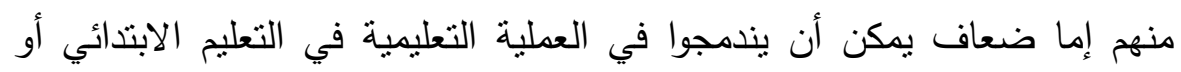
متخلفين عقليًا يجب أن يتم إدخالهم مدارس فكرية وذلك يرجع إلى متابعتهم الدورية

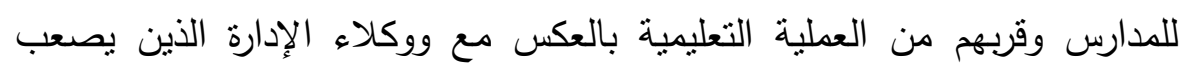
عليهم منابعة الفصل بشكل دوري ومن قرب كافي.

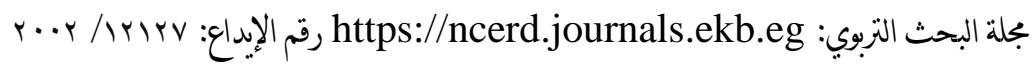

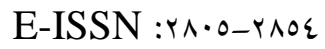

ISSN: $\cdot \wedge \Lambda \mu-17 \wedge V$ 
جدول (^): يوضح نتائج اختبار (ت) تبعًا لمتغير الوظيفة لمدارس الفصل الواحد (التعليم (المجتمعي)

\begin{tabular}{|c|c|c|c|c|c|}
\hline \multirow{2}{*}{ قاخبار ت } & \multirow{2}{*}{ الدلالة } & \multicolumn{2}{|c|}{ فترة ثقة = ه9 \% } & \multirow{2}{*}{ الاختلاف } & \multirow{2}{*}{ الصعوبات } \\
\hline & & الحد الأقصى & الحد الأدنى & & \\
\hline $1 \leqslant, Y \leqslant 0$ & $\cdot, \ldots$ & $r, r, 1$ & $1,7 \leqslant 0$ & $1,9 r \mu$ & الوظيفه \\
\hline
\end{tabular}

ونتائج اختبار (ت) جاءت بدلالة كبيرة بين محاور البحث مما يدل على أن هناك ارتباط كبير بين محاور البحث ما بدل اتفاق كلا من المشتركين في البحث من هن وكلاء الإدارة وموجهين المواد والمعلمين.أ في الرأي فيما يخص مدارس الفصل الواحد.

ثالثًا: - الإحصاء لمتغير المديرية التعليمية الجدول (9) الإحصاء الوصفية لمتغير الإدارة التعليمية لكل المحاور ونتائج

(تبار (ت) - (خت)

\begin{tabular}{|c|c|c|c|c|c|c|c|c|c|c|}
\hline \multicolumn{5}{|c|}{ 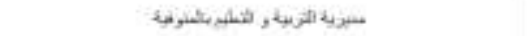 } & \multicolumn{5}{|c|}{ 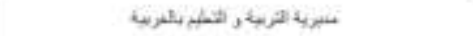 } & \\
\hline لفئ & سمد الرب & 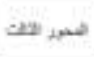 & له in & הis & الهين & صمري הקب & تصد صد & "لس & تلإنج & \\
\hline 115 & $\therefore \mathrm{A}$ & 27 & 84 & 4. & Tet & 10. & .95 & $\mathrm{Tri}$ & rts & $\pi$ \\
\hline $5,79 \cdot \%$ & 5.5177 & r,ve & $1,75 \mathrm{rr}$ & 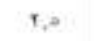 & reent & $1, A V=$ & $r, t r=$ & $x, \pi$ & $1, t+2 \pi$ & 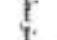 \\
\hline$+\pi$. & $+9+2$ & $0,01+1$ & $+A \times 11$ & *त्ता &., $17 / 5$ &,$+ 5 \times 2$ & $\triangle \forall T / A$ & +.5158 & $\forall \times(x)$ & $\frac{5}{8}$ \\
\hline$\cdot, \cdots$ & $\cdot, \cdots$ & $\bullet, \ldots$ & $\cdot, \cdots$ & $* \cdots$ & $\bullet, \cdots$ &,$+ \cdots$ & $+\cdots$ & $\cdot, \cdots$ & $\cdot, \cdots$ & $\frac{4}{6}$ \\
\hline$\cdot$, AnN & $\theta+$ Tle. &,$+ 8 \times 77$ & FTMA & $\cdot, 2 \times 58$ & $\cdot, x \wedge v$ &,+ 8 ket & $-2,1+4$ & t. FMAS &,$+ t>16$ & $\mathrm{t}$ \\
\hline
\end{tabular}

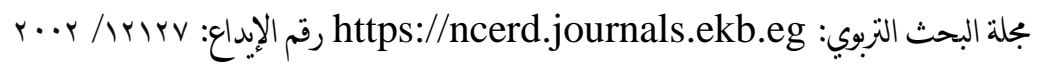

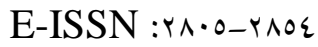
ISSN: $\cdot \Lambda \Lambda r-I T \Lambda V$ 
السنتالعشیون

حيث يتضح من الجدول الخاص المتوسطات الحسابية والانحراف المعياري لمتغير المديرية التعليمية (مديرية التربية والتعليم بالغربية - مديرية التربية والتعليم بالمنوفية) نجد انه عند مقارنة المتوسطات الحسابية في المحور الأول نجد أن أعلى متوسط فيه لمديرية المنوفية بمتوسط (Y,O) يليها مديرية الغربية بمتوسط $\cdot(r, \varepsilon \circ \wedge)$

ونجد انه عند مقارنة المنوسطات الحسابية في المحور الثاني نجد أن أعلى منوسط

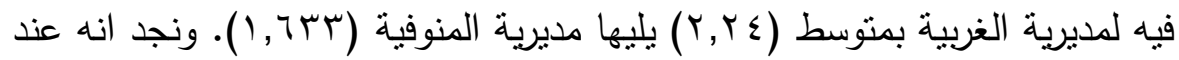
مقارنة المتوسطات الحسابية في المحور الثالث نجد أن أعلى متوسط فيه لمديرية المنوفية بمتوسط (Y,V0) يليها مديرية الغربية بمتوسط (Y0) (Y) ). ونجد انه عند مقارنة المتوسطات الحسابية في المحور الرابع نجد أن أعلى متوسط

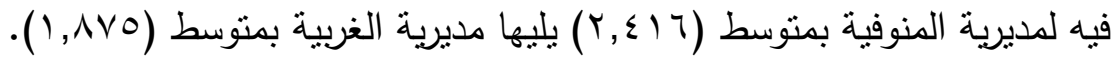
ونجد انه عند مقارنة المتوسطات الحسابية في المحور الخامس نجد أن أعلى متوسط فيه لمديرية المنوفية بمتوسط (.79,Y) يليها مديرية الغربية بمتوسط $\cdot(r, 00 \mathrm{~V})$ حيث يتضح من الجدول الخاص بالمقارنة بين جميع المحاور تبعًا لمتغير المديرية التعليمية بالمقارنة بين المتوسطات الحسابية لكل محور بمنيلة في المجموعتان للمديريتين التعليميتين (الغربية - المنوفية) نجد أن مديرية الغربية أخذت أعلى متوسط في المحور الأول والثاني لجذب الفئة المستهدفة وتسرب هذه الفئة من مدارس الفصل الواحد ونجد أن مديرية الغربية أخذت المتوسط الأعلى في باقي المحاور (الثالث والرابع والخامس) لاكتساب الطلبة المستوى التعليمي والمهارة اليدوية وانتظام العملية التعليمية للعاملين بالفصل الواحد وذلك بالرغم من انه لا توجد مدارس الفصل الواحد في أربع إدارات في مديرية المنوفية وهذا يطرح العديد

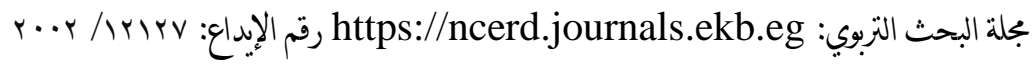

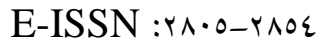

ISSN: $\cdot \wedge \wedge r-17 \wedge V$ 


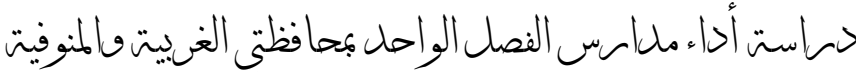

من الأسئلة مادام هناك هذا النجاح للمدارس في مديرية المنوفية لماذا لم يتم نشرة أم انه ليس مطابق للواقع وهل المستوى التعليمي المستهدف هو فلك الخط دون إجادة للقراءة والكتابة وباقي المواد من رياضة وعلوم ودراسات اجتماعية وعلوم ولغة انجليزية.

تم استخراج المتوسطات الحسابية والانحرافات المعيارية للمديريات التعليمية (مديرية التربية والتعليم بالغربية - مديرية التربية والتعليم بالمنوفية) كما تم استخدم اختبار (ت) لتحديد فترة التقة في العينات الواحدة.

كما تم استخدم اختبار (ت) لتحديد فترة التقة في العينة الواحدة. ونتائج اختبار (ت) جاءت بدلالة كبيرة بين محاور البحث مما يدل على أن هناك ارتباط كبير بين محاور البحث ما يدل اتفاق كلا من المشتركين في البحث من المديريتين في الرأي فيما يخص مدارس الفصل الواحد.

جدول ( • 1): نتائج اختبار(ت) لمتغير المديرية التعليمية

\begin{tabular}{|c|c|c|c|c|c|}
\hline \multirow{2}{*}{ قايمة } & \multirow{2}{*}{ | الدلالة } & \multicolumn{2}{|c|}{ فترة ثقة = هو\% } & \multirow{2}{*}{ الاختّلاف } & \multirow[t]{2}{*}{ الصعويات } \\
\hline & & الأقصى & الحد الأدنى & & \\
\hline $1 V, \leqslant 04$ &,$\ldots$ & $1, \leqslant 01$ & $\cdot, q \wedge r$ & 1,110 & التعليميتان \\
\hline
\end{tabular}

ولتحديد دلالة الفروق بين المتوسطات تم إجراء اختبار "تحليل التباين" كما هو مبين في

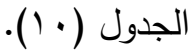

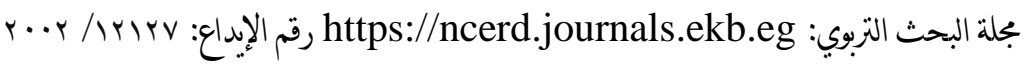

E-ISSN : r

ISSN: $\cdot \Lambda \Lambda r-I 7 A V$ 


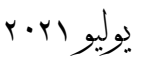
البكلا 1
$\varepsilon \cdot$ sul
السنت العشنقن

جدول (11): نتائج اختبار تحليل التباين الأحادي لالالة بين محاور البحث تبعا

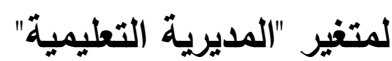

\begin{tabular}{|c|c|c|c|c|c|}
\hline الإحصنية & 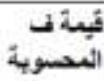 & المبريعتك يط & لرجت الحربة & عصدر التباين & 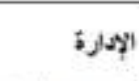 \\
\hline \multirow{3}{*}{$\cdots \cdots$} & \multirow{3}{*}{.90} & Av & + & ين كجس عات & \multirow[t]{3}{*}{ العحوز الأول } \\
\hline & & $3,7 y=$ & "r & داخل المجيو عات & \\
\hline & & & it & العجوع & \\
\hline \multirow{3}{*}{$\cdots+$} & \multirow{3}{*}{.$+r y$} &.,$\pi r$ & $\tau$ & بين المجموعك & \multirow[t]{3}{*}{ المحوز ألثاتي } \\
\hline & & $3,7: 5$ & $\pi$ & داكل المجسو عات & \\
\hline & & & it & المجبوع & \\
\hline \multirow{3}{*}{.$+\mathrm{TV}$} & \multirow{3}{*}{$\mathrm{Trt}$} & $9,2 \mathrm{A4}$ & r & بي العجر عاك & \multirow[t]{3}{*}{ ألعدور ألثاكي } \\
\hline & & $t, r \in A$ & $r$ & داخل المجسو عاك & \\
\hline & & & it & المجسوع & \\
\hline \multirow{3}{*}{$\ldots$} & \multirow{3}{*}{$A, \otimes A}$, & 01,147 & 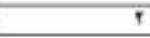 & بل نسجر عاك & \multirow[t]{3}{*}{ المحرد الزرايب } \\
\hline & & $3,0 \mathrm{At}$ & $"$ & داخل أمجبو عاك & \\
\hline & & & it & التجبوع & \\
\hline \multirow{3}{*}{$\cdots \cdots$} & \multirow{3}{*}{$\therefore 1 t$} & 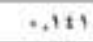 & 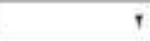 & بذل الفجسو عاك & \multirow[t]{3}{*}{ ألعدور الخالبس } \\
\hline & & $1,+v_{1}$ & $\pi$ & داكل المجير عك & \\
\hline & & & it & المجبوع & \\
\hline
\end{tabular}

تتير نتائج الجدول السابق إلى وجود فروق بسيطة في كل المحاور باستثناء

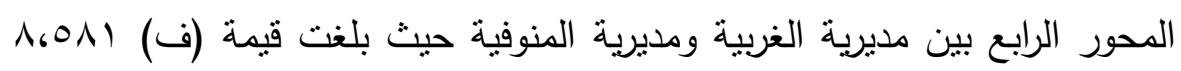
ومنه يتبين وجود فروق ذات دلالة إحصائية تعزى لمتغير "المديرية التعليمية" في

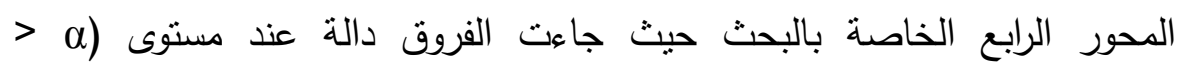
$\cdot(\cdot 6 \cdot 0$

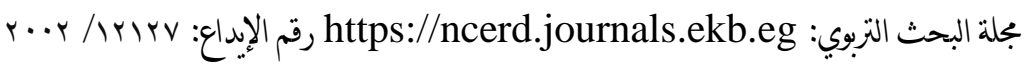

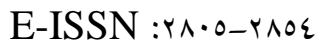

ISSN: $\cdot \wedge \wedge \mu-I 7 \wedge V$ 


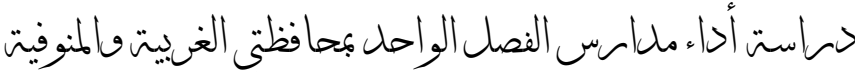

\section{رابعاً: الإحصاء لمتغير الخبرة}

جدول (Y I ): المتوسطات الحسابية والانحرافات المعيارية) لمتغير الخبرة لمحاور البحث لاراسة أداء (الفصل الواحد) التعليم المجتمعي وليطي

\begin{tabular}{|c|c|c|c|c|c|c|c|c|c|c|c|c|c|c|c|}
\hline \multicolumn{5}{|c|}{ 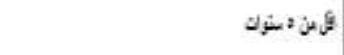 } & \multicolumn{5}{|c|}{ من بلو السئرك } & \multicolumn{6}{|c|}{ فرنز من ، 1 سئرت } \\
\hline |س & ترتي & $=$ & 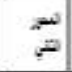 & - & تسم: & تئي & 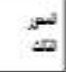 & تصن & 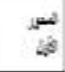 & س & 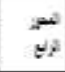 & 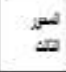 & w & 宓 & \\
\hline$r, 4, \tau$ & , Ant? & $x, 2 \pi m$ & t, 7119 & 0,0 & T,Yast & 1,2110 & $T, 4 \%$ & $x, 12$ & r,takr & r,ilor & $7, \% \cdot \psi$ & $0,+2.4$ & $t, \ldots+\%$ & $\nabla: t \leqslant N \mid$ & \\
\hline , & , & 年, & , $35 \mathrm{r}$ & דזוצי. & 列, & . & 0,3794 & . & Ais. & 保, & -, 4 . & 政, & ,, 31.4 & . $M m$ & $\{t$ \\
\hline
\end{tabular}

حيث يتضح من الجدول الخاص المتوسطات الحسابية والانحراف المعياري لمتغير الخبرة (أكثر من · ( سنوات - من هالى • ( سنوات - اقل من 0 سنوات) نجد انه عند مقارنة المتوسطات الحسابية في المحور الأول نجد أن أعلى متوسط للموجهين بخبرة اقل من 0 سنوات بمتوسط (r,0) يليها للموجهين بخبرة أكثر من

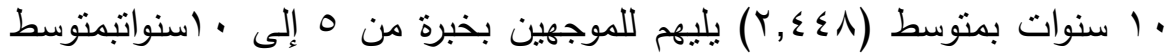
$\cdot(r, 乏 \circ \Lambda)$

من النتائج المتوسطات ولانحرافات لكل من المحور الأول والثاني يتضح أن الطلبة يتم تسجيلها بمدارس الفصل الواحد والطلبة تتسرب من مدارس الفصل مل ملت

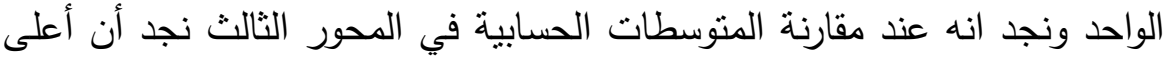
متوسط فيه للموجهين بخبرة من 0 إلى · اسنوات بمتوسط (Y) (Y) يليها

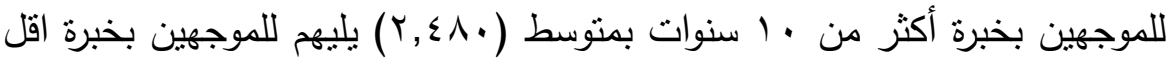

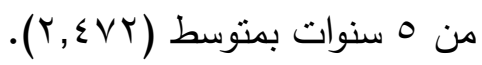
ونجد انه عند مقارنة المتوسطات الحسابية في المحور الرابع نجد أن أعلى متوسط بن

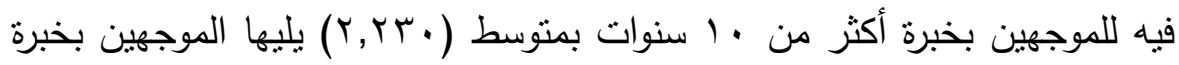

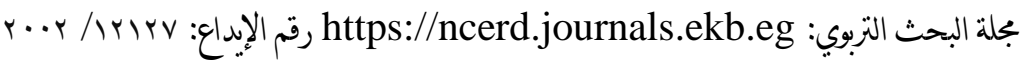

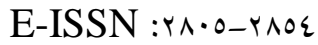

ISSN: $\cdot \Lambda \Lambda r-I 7 \wedge V$ 
اقل من 0 سنوات بمنوسط (1آ人, 1) يليهم للموجهين بخبرة من ه إلى • اسنوات

$$
\text { بمتوسط (1,07) (1,0). }
$$

ونجد انه عند مقارنة المتوسطات الحسابية في المحور الخامس نجد أن أعلى

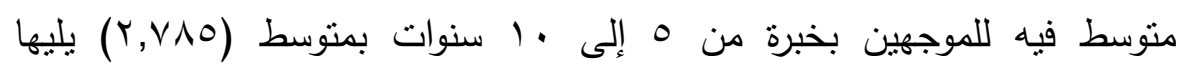

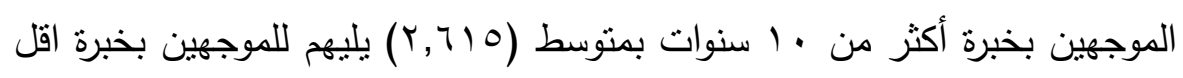

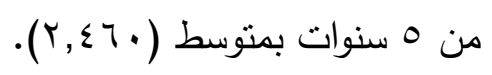

حيث يتضح ارتفاع درجة نسرب الطلبة من مدارس الفصل الواحد حيث بلغ المتوسط الحسابي للأولى (111) حرفة يدوية حيث لم يزد عن (ro7، 1 ) مما يدل على عدم إجادة الطلبة للحرف. وبتقدير فترة الثقة يتبين الأثر السلبي لتسرب الطلبة وعدم إجادتهم للحرف اليدوية التي هي الأساس في مدارس الفصل الواحد ولذلك تم عمل اختبار ت لمتغير الخبرة.

ونتائج اختبار (ت) جاءت بدلالة كبيرة بين محاور البحث مما بدل على ان هناك ارتباط كبير بين محاور البحث مما يدل اتفاق كلا من المشتركين في البحث تبعا لمتغير الخبرة في الرأي فيما يخص مدارس الفصل الواحد.

\begin{tabular}{|c|c|c|c|c|c|}
\hline & & & & \multicolumn{2}{|c|}{ (التعليم المجتمعي) } \\
\hline \multirow{2}{*}{ قيمة اختبار } & \multirow[t]{2}{*}{ مستوى الدلالة } & \multicolumn{2}{|c|}{ فترة ثقة = هq } & \multirow{2}{*}{ الاختلاف } & \multirow[t]{2}{*}{ الصعويات } \\
\hline & & الحد الأقصى & الد الأدنى & & \\
\hline $19, \times 19$ & $\cdot, \ldots$ & $1,9 \times 1$ & $1, \varepsilon V Y$ & $1, \wedge \leq 4$ & متغير الخبرة \\
\hline
\end{tabular}
جدول (M I): يوضح نتائج اختبار (ت) تبعًا لمتغير الخبرة لمدارس الفصل الواحد

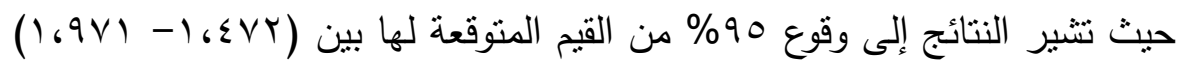
بمستوى دلالة يقل عن (0.، •). ولتحديد دلالة الفروق بين المتوسطات ثم إجراء اختبار "تحليل التباين" كما هو مبين في الجدول (ع ( ).

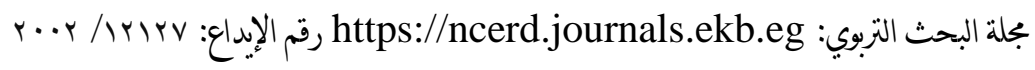

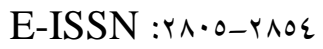
ISSN: $\cdot \wedge \wedge r-17 \Lambda V$ 


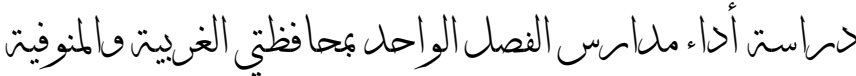

جدول (؛ 1): نتائج اختبار تحليل التباين الأحادي لدلالة بين محاور البحث تبعا لمتغير "الخبرة"

\begin{tabular}{|c|c|c|c|c|c|}
\hline الإحصائية & قالمسسوية ف & متوبط المربعات & الحرية & مصدر التباين & الإدارة \\
\hline \multirow{3}{*}{$\cdot 6 \cdots$} & \multirow{3}{*}{.807} & $\varepsilon, 0 \ldots$ & r & بين المجموعات & \multirow{3}{*}{ الأولور } \\
\hline & & 0,900 & $r r$ & داخل المجموعات & \\
\hline & & & $r \leq$ & المجموع & \\
\hline \multirow{3}{*}{$\cdot 6 \cdots$} & \multirow{3}{*}{.119} & $1,17 \mathrm{~V}$ & r & بين المجموعات & \multirow{3}{*}{ الثحور } \\
\hline & & $Y, Y \circ \Lambda$ & $r r$ & داخل المجموعات & \\
\hline & & & $r \leq$ & المجموع & \\
\hline \multirow{3}{*}{$\cdots \cdots$} & \multirow{3}{*}{.rrq } & $\cdot, 9 \wedge \mathrm{V}$ & $r$ & بين المجموعات & \multirow{3}{*}{ الثحور } \\
\hline & & $\varepsilon, r \cdot r$ & $r r$ & داخل المجموعات & \\
\hline & & & $r \leq$ & المجموع & \\
\hline \multirow{3}{*}{$\cdots \cdots$} & \multirow{3}{*}{$1, \varepsilon r r$} & $1 \leq, V 7 V$ & $r$ & بين المجموعات & \multirow{3}{*}{ المحور } \\
\hline & & $1 \cdot, \mathrm{r} \vee \wedge$ & $r r$ & داخل المجموعات & \\
\hline & & & $r \leq$ & المجموع & \\
\hline \multirow{3}{*}{$\cdots \cdots$} & \multirow{3}{*}{.911} & $\Lambda, \wedge r$. & r & بين المجموعات & \multirow{3}{*}{ الخامس } \\
\hline & & $9,7 \wedge r$ & $r r$ & داخل المجموعات & \\
\hline & & & $r \leq$ & المجموع & \\
\hline
\end{tabular}

تتير نتائج الجدول السابق إلى وجود فروق بسيطة في كل المحاور باستثاء المحور الرابع بين كل من وكلاء الإدارات والموجهين والمعلمين أ حيث بلغت قيمة

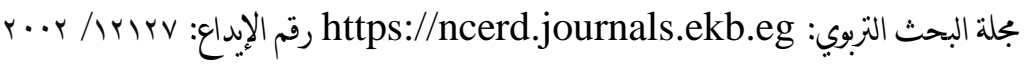

E-ISSN : r

ISSN: $\cdot \Lambda \Lambda r-I 7 A V$ 


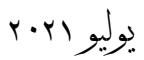

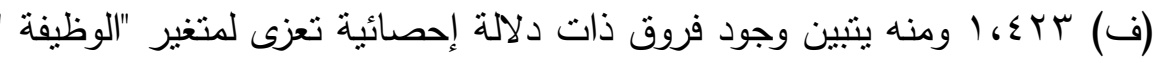

في المحور الرابع الخاص بالبحث حيث جاءت الفروق دالة عند مستوى (م إندي $\cdot(\cdot 6 \cdot 0$

جدول (0 1 ): العلاقة بين متغيرا ت البحث

\begin{tabular}{|c|c|c|c|c|}
\hline الوظيفة التي & الخبرة & التعليمية & & \\
\hline$-\cdot, \mid \wedge \wedge$ & $-\cdot, 1 \wedge \varepsilon$ & 1 & $\begin{array}{c}\text { Pearson } \\
\text { Correlation }\end{array}$ & \multirow{2}{*}{ التمديرية } \\
\hline rq & rq & $r q$ & العدد & \\
\hline., 179 & 1 & $-\cdot, \mid \wedge \leq$ & $\begin{array}{c}\text { Pearson } \\
\text { Correlation }\end{array}$ & \multirow[t]{2}{*}{ الخبرة } \\
\hline rq & rq & rq & العدد & \\
\hline$-\cdot, \mid \wedge \wedge$ &., 179 & 1 & $\begin{array}{l}\text { Pearson } \\
\text { Correlation }\end{array}$ & \multirow{2}{*}{ 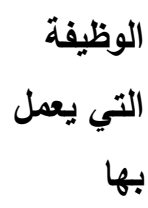 } \\
\hline rq & Y & rq & العدد & \\
\hline
\end{tabular}

وعند القيام بعمل دراسة للعلاقة بين متغيرات البحث وجد انه لا يوجد علاقة بين المديرية التعليمية والخبرة وأعطت نتيجة سالبة ولا يوجد علاقة بين الخبرة والمديرية

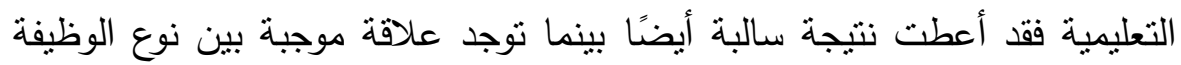
التي يعمل بها والخبرة ومن الممكن أن يرجع ذلك إلى أن ارتفاع عدد سنوات الخبرة

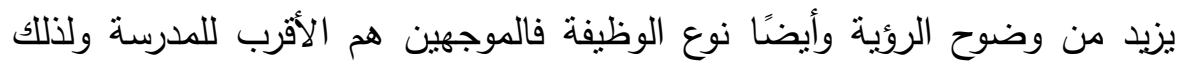
يكون هناك وضوح لروئة.

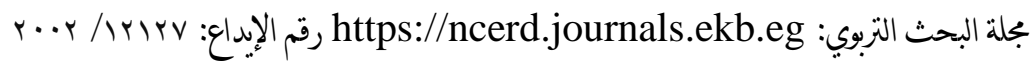

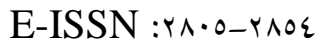




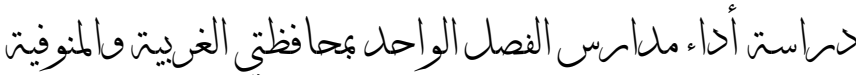

مقترحات حضرات الموحهين العاملين بالإدارات التعليمية التي استهدفها البحث وقاموا بالتوجيه على مدارس الفصل الواحد (مدارس التعليم المجتمعي) واشتتركوا

في البحث

- ل ال تستطيع مدرسة الثقافة للمستويات "الرابع والخامس والساد" الإلمام بالمواد التي تقوم بتدريسها بشكل جيد.

- غياب حضور العاملين بالمدرسة يخص مشرفة الفصل الواحد وله ما له

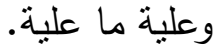

- الغياب بمدارس الفصل الواحد يتم التلاعب به للطلاب والعاملين.

- يقوم التلاميذ بأعمال بسيطة جدًا ولا يهم الجميع سوى الحفاظ على العهدة

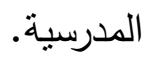

- عدد الطلاب من r:0 طلاب وغالبًا لا يحضرون.

- الموجهين يرفضون التوجيه على مدارس الفصل الواحد وهذا نوع من

الرفض الصامت لمدارس الفصل الواحد.

- - المهارات التي يكتسبها الطلاب تكفي فقط لمتطلبات الحياة اليومية. - التلاميذ المتواجدين في المدارس فئة منهم يمكن تواجدها في المدارس العادية والفئة الأخرى تدخل مدارس التربية الفكرية.

\section{مـلاحظــات الـبــاحـث}

نظرًا لأني أعمل في مدارس الفصل الواحد منذ 9/ . . . بم إلى

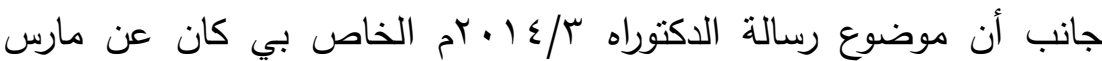
الفصل الواحد "التعليم المجتمي " وتطلب إتمام درة الدكتوراه القيام بعمل استبانة تطلب مني الذهاب لبعض مدارس الفصل الواحد التابعة لمديرية التربية التعليم بالغربية.

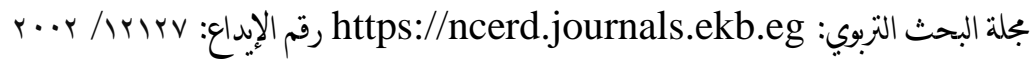

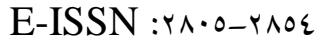

ISSN: $\cdot \Lambda \Lambda r-I T \Lambda V$ 
السنت العشنفن

\section{فقد وجدت الآتي:}

لا يتم توزيع المدارس تبعًا لخريطة نربوية في المناطق التي ذهبث إليها حيث وجدت معظم المدارس ملحقة بمدارس ابتدائي والمدارس المستقلة في مناطق لبست بحاجة إليها. يوجد بمدارس الفصل الواحد أدوات وخامات لم تتاح لي وأنا طالبة " كلية الاقتصاد المنزلي "تزبوي" (دبلوم وماجستير ودكتوراه) جميعهم في الملابس والنسيج في نفس كلية الاقتصاد المنزلي بشبين الكوم". عند ذهابي لإحدى المؤسسات المسؤولة عن الفصل الواحد والتعليم المجتمي وجدت على جهاز الحاسوب الخاص بأحد المسؤولين صور لمدارس فصل واحد مستقلة في أماكن ظهر أنها في حاجة ماسة لها قد ثم تخريبها وعند سؤالي لوكيل الوزارة المسؤول عمن الفاعل أجاب بأن المستهدفين وأولياء أمورهم هم من خربوا المدارس وعندما سألت عن السبب لم أحصل على إجابة. بالتذقيق في المقارنة الخاصة بمدارس الفصل الواحد في السبعينات والتسعينات من الممكن أن تلاحظ بسهولة أنه لا يوجد فروق جوهرية ونجد أن مدارس بارس الفصل الواحد في السبعينات في نهاياتها استقبلت طلاب ذكور ثم أغلقت هذه بهن

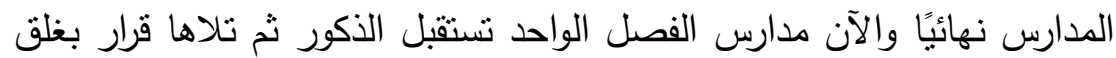
المدارس التي يقل عدد التلاميذ فيها عن خمس طلاب (مدارس ملحقة أو مدارس مسنقلة).

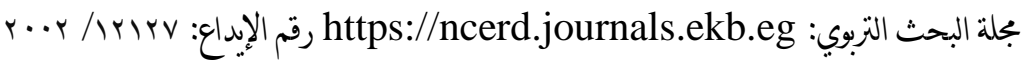

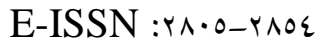
ISSN: $\cdot \wedge \Lambda \mu-17 \wedge V$ 


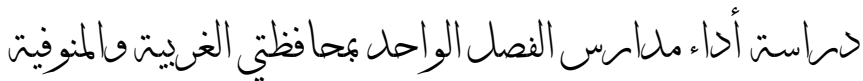

جدول (r) مقارنة بين مدرسة الفصل الواحد في السبعينات والتسعينات

\begin{tabular}{|c|c|c|c|c|}
\hline \multirow{2}{*}{ مشرسة التسميلت } & \multirow{2}{*}{ مذرسة السبعيتك } & \multicolumn{2}{|r|}{ رجه ألملارية } & \multirow[b]{2}{*}{ ? } \\
\hline & & جزيلك & مدلز & \\
\hline 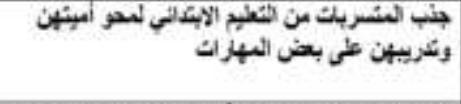 & 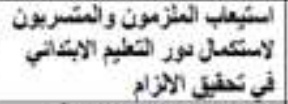 & الثيث & \multirow{8}{*}{ 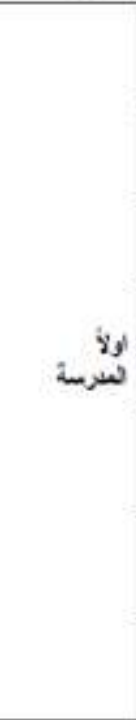 } & , \\
\hline 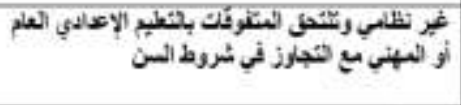 & 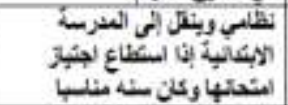 & 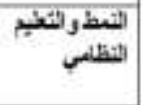 & & * \\
\hline 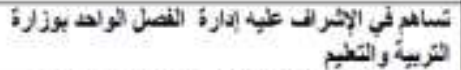 & 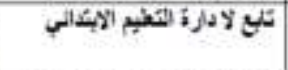 & ij/ & & $r$ \\
\hline 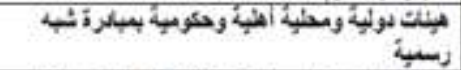 & 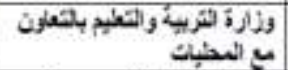 & ألتصويز & & 1 \\
\hline 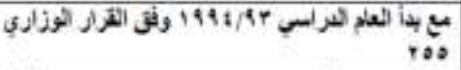 & 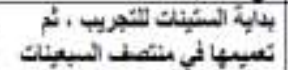 & 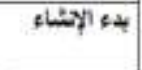 & & s \\
\hline 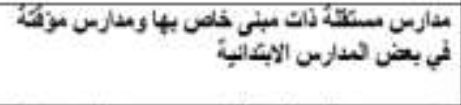 & 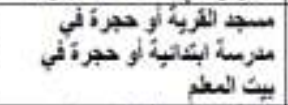 & مبنى العنزسة & & १ \\
\hline 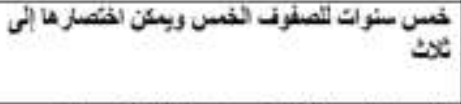 & 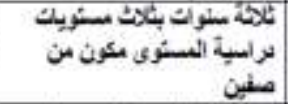 & |نساست & & $v$ \\
\hline 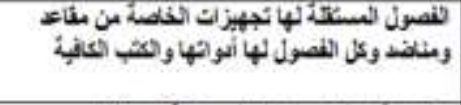 & 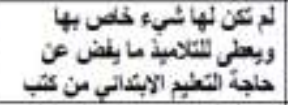 & | ونهيزات & & $A$ \\
\hline 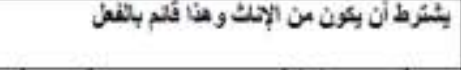 & 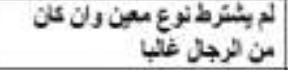 & ألتوع & \multirow{4}{*}{ ثلبا المطنون } & 4 \\
\hline 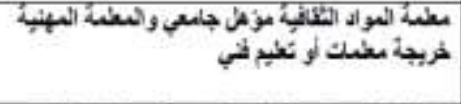 & 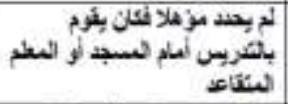 & 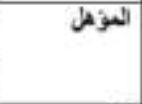 & & 3 \\
\hline 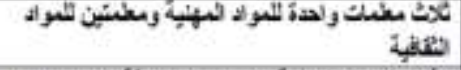 & 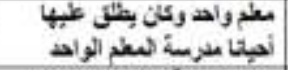 & ألعثد & & $w$ \\
\hline 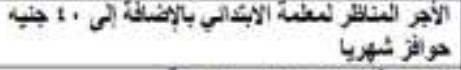 & 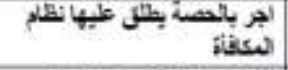 & الأجزد & & $1 \%$ \\
\hline 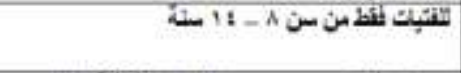 & 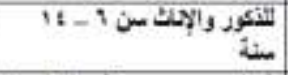 & ألموع والهن & كتيا البازسون & it \\
\hline 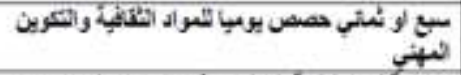 & 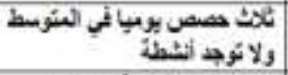 & الخطنة & \multirow{3}{*}{ 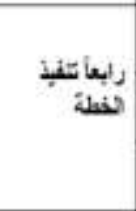 } & 14 \\
\hline 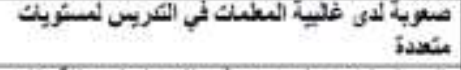 & 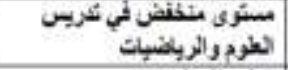 & كيبة المتريسل & & 10 \\
\hline 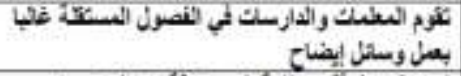 & بطلر التصل شتبا & أسعينت & & 19 \\
\hline 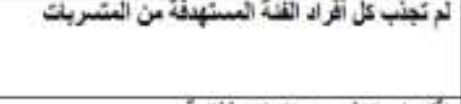 & 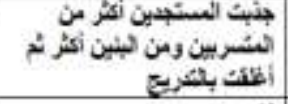 & البحثدة التمت & \multirow[t]{2}{*}{ خانساً الثتلتج } & iv \\
\hline 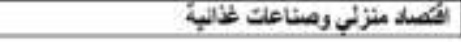 & AभY & ألمبرات & & 11 \\
\hline
\end{tabular}

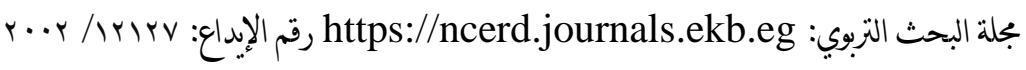

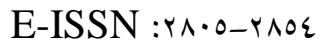

ISSN: $\cdot \Lambda \Lambda r-I T \Lambda V$ 
السنتصالعشטقن

\section{المراجع}

\section{أولَا: الرسائل العلمية.}

ا . رحاب طلعت محمود -فاعلية استخدام بعض إستراتيجيات التعليم التفريدي بمدارس الفصل الواحد في تتمية بعض مهارات اللغة العربية والاتجاه نحوها / 9 . . •.م / جامعة القاهرة، / معهد الدراسات التربوية -قسم المناهج وطرق التدريس.

r ـ ـاطمة فوزي عبد العاطي - مدرسة الفصل الواحد بين السبعينات والتسعينات مجلة البحوث النفسية والتربوية - كلية التربية - جامعة المنوفية -العدد الثالث السنة الثالثة عشر 991 (م. م.

ץ . محمد عبد العال محمد - تطوير أداء مدارس التعليم الأساسي على ضوء

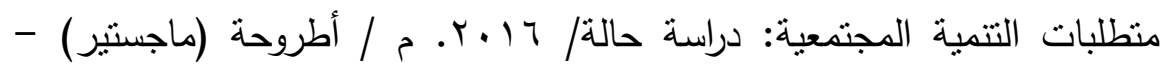
جامعة أسيوط. كلية التربية. قسم أصول التربية. ـ ـ محمد علي علي- تقويم برنامج التعليم المجتمي بمدارس الفصل الواحد

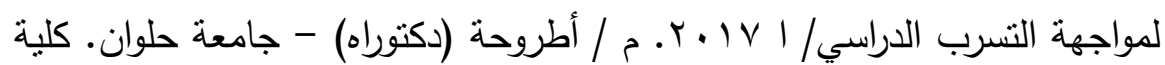
الخدمة الاجتماعية. قسم تتظيم المجتمع. 0. محمد صالح عبد الحميد صالح - آليات مساعدة الصناعات الصغيرة والمتوسطة في مجال صناعة الملابس الجاهزة - رسالة ماجستير - كلية الاقتصاد المنزلي قسم الملابس والنسيج- جامعة المنوفية - م . . ب م. 7 ـ . معتز أحمد إبراهيم -تتظيم منهج الرياضيات بالصفوف الثلاثة الأولى في ضوء فلسفة مدرسة الفصل الواحد وقياس فعاليته في تحصيل التلميذات وأداء المعلمات

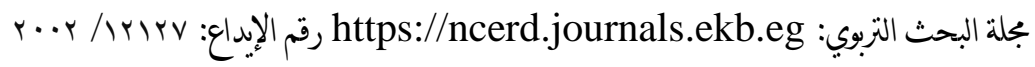

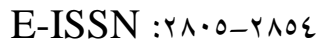

ISSN: $\cdot \wedge \Lambda \mu-17 \wedge V$ 


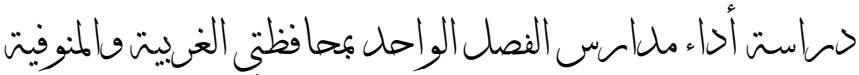

- جامعة حلوان - كلية التربية - قسم المناهج وطرق التدريس - رسالة دكتوراه -

$$
\text { - } 1
$$

V ـ مشيرة إبراهيم صابر -مشكلات مدارس الفصل الواحد في مصر ومواجهتها في

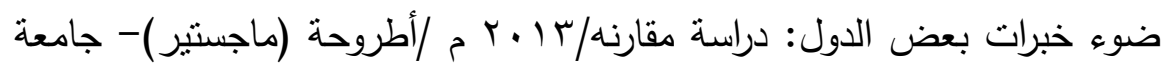
بنها. كلية التربية. قسم التربية المقارنة.

1. منى مصباح إبراهيم- منطلبات تفعيل مدارس التعليم المجتمعي للفتيات في جمهورية مصر العربية / 10 ـ r. م /أطروحة (ماجستير) -جامعة المنصورة. كلية

$$
\text { التربية. قسم أصول التربية الهمبنه }
$$

9 ـ ـ نجلاء عبد القوي عبد الوهاب-واقع مدارس الفصل الواحد والفصول متعددة المستويات للفتيات بمحافظة المنيا -رسالة ماجستير -كلية التربية - قسم أصول

$$
\text { ثانيًا: الكتبة- جامعة المنيا - ع . . ب م. }
$$

• ا ـ وزارة التربية والتعليم / المركز القومي للبحوث التريوية والتنمية: دليل الميسرة إلى التعليم المجتمعي - إدارة الفصل الواحد - تم إعداد هذا الدليل بدعم من

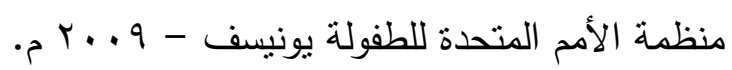

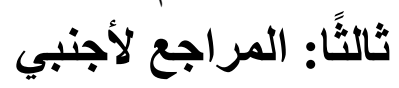

11. A. Green, Education and State Formation: The Rise of Education Systems in England, France, and the USA. Macmillan, 1990

12. Chesnut, Mary Boykin Miller (1980). A Diary from Dixie. Harvard University Press. p. 233. ISBN 9780674202917 .

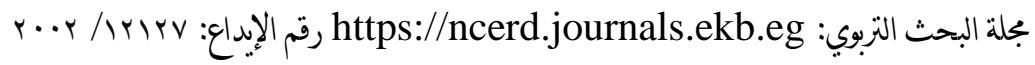

E-ISSN : r

ISSN: $\cdot \Lambda \Lambda r-I T \Lambda V$ 


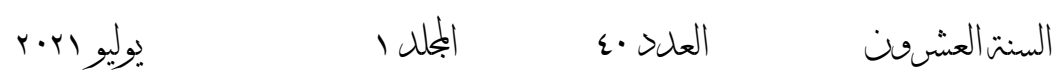

13. Cubberley, Ellwood P. (1919). Public Education in the United States.

14. Conant, The American High School Today (New York: McGraw-Hill, 1959).

15. Diane Ravitch, The Revisionists Revised: A Critique of the Radical Attack on the Schools (1978).

16. Diane Ravitch, Left Back: A Century of Failed School Reforms (2000), p. 169; David Tyack, The One Best System: A History of American Urban Education (1974).

17. Durst, Anne (July 2010). Women Educators in the Progressive Era (First ed.). New York: Palgrave Macmillan... ISBN 978-0-230-61073-6.

18. Dunlop, O. J. (1912). "iv". English Apprenticeship and Child Labour, a history. London: Fisher Unwin.

19. Distinctive and Inclusive the National Society and Church of England Schools 1811-2011 The National Society Church House Great Smith StreetLondonSW1P 3AZPublished 2012 by the National Society Copyright $\odot$ The National Society 2012 Front Cover image: () Dean \& Chapter of Westminster/Picture Partnership.

20. Edward Pauly, The Classroom Crucible (New York: Basic Books, 1991), underscores parents' keen interest in picking the best classroom for their children, a form of "choice" widespread long before the choiceof schools was possible.

21. Egypt: Education for All 2015 National Review

22. Floyd W. Reeves, ed., Education for Rural America (Chicago: Uni-versity of Chicago Press, 1945),

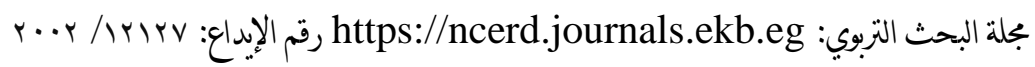

E-ISSN :YN・O-YNOE

ISSN: $\cdot \wedge \wedge r-17 \wedge V$ 
p. 127; and Kathleen Weiler, Country School women Teaching in Rural California, 18501950(Stanford, Calif.: Stanford University Press, 1998)

23. Groen, Mark (2008). "The Whig Party and the Rise of Common Schools, 1837-1854". American Educational History Journal. 35 (1/2): 251260.

24. Graham, P.A. 1974). Community and Class in American Education, 1865-1918. New York: Wiley .

25. Gillard, Derek (2018). Education in England: A History. Retrieved 3 August 2018.

26. "Monitorial system", Britannica Encyclopedia (online ed.)

27. Messerli, Jonathan (1972). Horace Mann: A Biography.

28. Moses, Montrose J. (1907). Children's Books and Reading. New York: Mitchell Kennerley. p. 103. Robert Raikes.

29. MAINSTREAMING AND SUSTAINING THECOMMUNITY SCHOOL MODEL IN EGYPT: A FORMATIVE EVALUATION Submitted to UNICEF Country Office, Cairo by Dr. Samira Sidhom and Al-Fustat

30. James J. Hennesey, American Catholics: A History of the Roman Catholic Community in the United States (1983).

31. Jurgen Herbst, The Once and Future School: Three Hundred and Fifty Years of American Secondary Education (1996)

32. John Dewey, My Pedagogic Creed (1897).

33. Key dates in British Education (1000-1899) ThePotteries.org

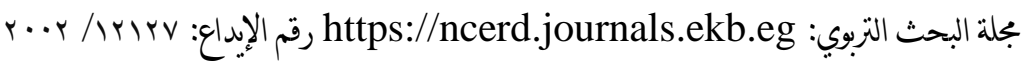

E-ISSN : r

ISSN: $\cdot \Lambda \Lambda r-I T \Lambda V$ 


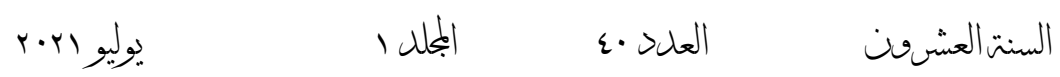

34. Langford, Paul (1984). "7 - The Eighteenth Century". In Kenneth O. Morgan (ed.). The Oxford Illustrated History of Britain. Oxford: OUP. p. 382. ISBN 0-19-822684-5.

35. Lincolnshire School Resources Archived 2008-08-30 at the Way back Machine Genuki.org.uk

36. Link, p. 128; Francis T. Spaulding, The Small Junior High School (Cambridge, Mass.: Harvard University Press, 1927), chap. 8; and Weil-er,

37. Peterson, Paul E. (2010). Saving Schools: From Horace Mann to Virtual Learning.

38. Paul Peterson, Saving Schools: From Horace Mann to Virtual Learning (2010).

39. Ravitch, Diane (1978). The Revisionists Revised: A Critique of the Radical Attack: the schools. Basic Books.

40. Selwyn K. Troen, The Public and the Schools: Shaping the St. Louis System 1838-1920 (1975) pp 151, 224-26, quoted in Ravitch, The Revisionists Revised.

41. "Schooling before the 19th Century". Living Heritage. UK Parliament. Retrieved 1 December 2014.

42. School District Organization (Washington, D.C.: American Association of School Administrators, 1958), and James B. Conant, The American High School Today (New York: McGraw-Hill, 1959).

43. Strategic Plan for Pre-University Education 2014 - 2030 Education Egypt National Project Together We Can - The Strategic Plan of Pre-University Education $2014-2030$

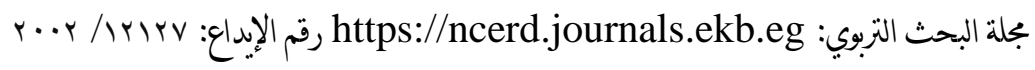

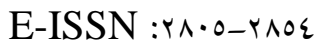
ISSN: $\cdot \wedge \Lambda \mu-I T \Lambda V$ 
44. Thomas C., ed. (2010). "Age Grading". Encyclopedia of Educational Reform and Dissent, See in Hunt.

45. Timothy Walch, Parish School: American Catholic Parochial Education from Colonial Times to the Present (2003).

46. William J. Reese, "The Origins of Progressive Education," History of Education Quarterly 2001 41(1): 124.

47. Walvin, J (1982). A Child's World. A social history of English childhood 1800-1914. London: Pelican. ISBN 0-14-022389-4.

48. William W. Cutler III, "Cathedral of Culture: The Schoolhouse in American Educational Thought and Practice Since 1820," History of Education Quarterly, Spring 1989.

49. Zuczek, Richard (2015). Reconstruction: A Historical Encyclopedia of the American Mosaic. ABC-CLIO. p. 172. ISBN 9781610699181.

\section{رابعًا: مواقع الإنترنت}

50. http://www.ahlycairo.com

51. amercan $\% 20$ education/Education $\% 20$ to $\% 20$ the $\% 20$ Masse s\%20-\%20US\%20History\%20Scene.html

52. https://www.thenewsstar.com/story/news/local/2016/05/27/naviga tion-school-monroe-nations-largest/84927028/

53. http://www.educationengland.org.uk/history/chapter03.html

54. https://journals.sagepub.com/doi/pdf/10.1177/0031721702 08300508

55. "Research Details". Heinz.cmu.edu .

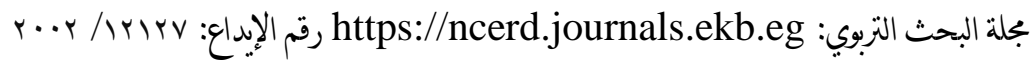

E-ISSN : r

ISSN: $\cdot \Lambda \Lambda r-I T A V$

$$
\text { ros }
$$

